\title{
Identity and Exchangeable of Figure and Background Visually
}

\author{
Basim Hasan Hashim Al-Majidi
}

Ahmed Hashim El-Eqapy

Architectural Engineering Department, University of Technology, Baghdad-Iraq

90004@uotechnology.edu.iq

90047@uotechnology.edu.iq

\section{\begin{tabular}{|l|l|l|} 
Submission date:- 5/10/2017 & Acceptance date:- 22/2/2018 & Publication date:-13/2/2019
\end{tabular}}

\begin{abstract}
:
Studies has focused generally on studying generally and specific researches concepts in architecture, one of these concepts was the identity and the ways that support constructing and specifying the identity concept with in various frames, but it ignore important side which represented by experimenting two points which they are the figure and background visually and the exchangeable connection and the effect of each one of them on the other in forming the general frames to identity in sight of architectural knowledge frame around all identity and its relationships with figure and background visually.

This paper aims to define the general visions to study the identity concept in general and the effect of figure and background visually and the exchangeable effect between them in constructing the basis of this new identity by specifying the knowledge proposition about the general subject then build a theoretical frame for these concepts and apply it on specific architectural case study representing a practical example of the identity concept in architecture and analyzing the results of about there are approximate in nature and level of results of figure and background visually and its relationship exchangeable with identity.
\end{abstract}

Keywords: Identity, Spatial figure, Figure and Background Visually, Exchangeable. 


\title{
الهوية وتبادليه علاقة الثكل و الخلفية بصريا
}

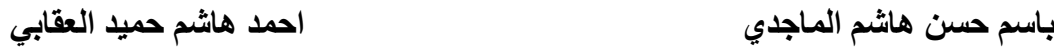 \\ قسم هندسة العمارة، الجامعة التكنولوجية، بغد/د- العراق
}

\section{7@uotechnology.edu.iq}

90004@uotechnology.edu.iq

الخلاصة:

ركزت الطروحات بشكل عام و البحوث المتخصصة على در اسه مفاهيم متتو عة مهمة ضمن حقل العهــارة ومسـن ضـــنها

مفهوم الهوية و اليات وسبل دعم تنكيلها وتحديدها ضمن اطر متتوعة، الا انها اغفلت جانبا مهما دون الخوض فيه منمثنلا باختبـار

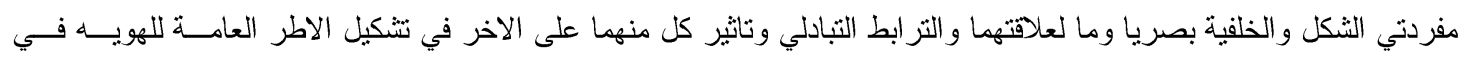
ضوء الإطار المعرفي المعماري العام حول الهويه و علاقاتها بالثنكل و الخلفيه بصريا.

يهدف البحث الى تحديد الرؤى العامة لدر اسة مفهوم الهوية بشكل عام واثر مفردتي الثنكل والخلفية بصريا والتاثير التبادلي بينهما في تتكيل اسس تلك الهوية بتحديد الطرح المعرفي العام حول كل ما سبق ومن ثم التوجه لبناء اطر نظريه متعددة لمؤشر ات تلاك المفاهيم ونطبيقها على نتاج معماري متخصص يمثل تطبيق فعلي لحاله المفهوم الاساسي (الهوية) في العمارة وتحليل نتائج ذلك

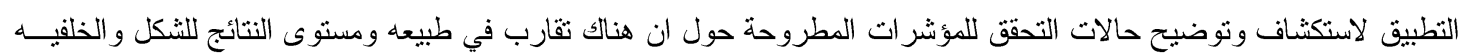
بصريا وعلاقتها النبادلية مع مفهوم الهويه. الكلمات الداله: الهوية، التشكيل، الثنكل و الخلفية بصريا، التبادلية.

تعاملت الطروحات العامة في در استة مفاهيم وجو انب مؤثزة في حقل العمارة عادة ما ينم نتاول بعضـــها بصـــورة منفــردة

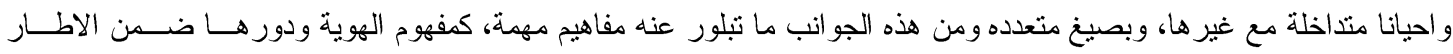
المعماري العام ولذا وجب التركيز على مفردات أخرى مهمة ومساعدة في صياغه اطر مفهوم الهوية وضمن حالة معرفية لم يتم

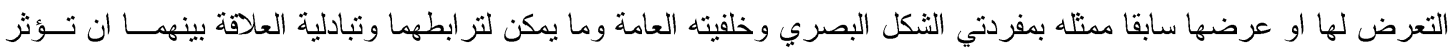

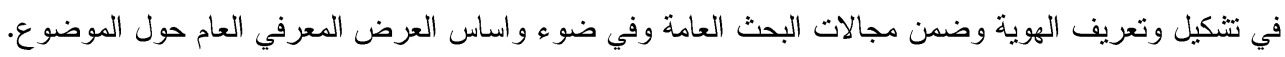

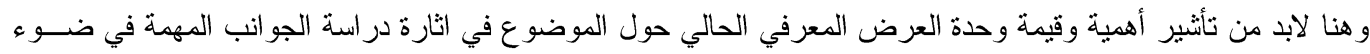

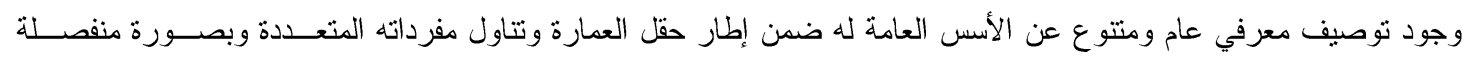

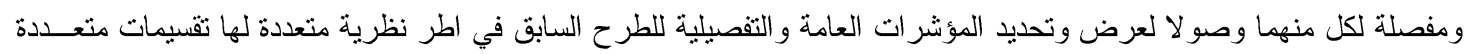

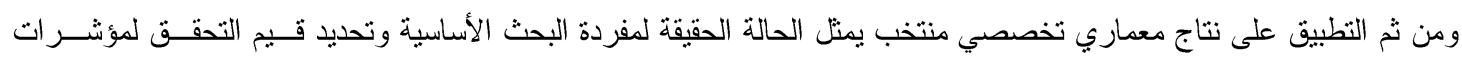
الأطر وعرض ومناقتشة وتحليل النتائج بشكل عام وتفصيلي وعرض الاستتناجات النهائية عن الموضوع.

وعليه جاعت مشكلة البحث المعرفية بصيفه: -

(ضعف وضوح التصور المعرفي حول أثر مفهومي (الثنكل والخلفية بصريا) على تحديد المدى المتاح للتغيــر و التبادليــة

لمفهوم الهوية).

(ما هدف البحث فقد ركز على: -

(توضيح التصور المعرفي حول أثز مفهومي (الثنكل و الخلفية بصريا) على تحديد المدى المتاح للتغير و التبادليــة لمفهـوم

الهوية). 


\section{ولغرض حل مشكلة البحث المعرفية وتحقيق الهاف سيصار الى: -}

• بناء إطار معرفي نظري يتم فيه استعر اض وتحديد الجو انب المرتبطة بالمؤشر ات النظرية الخاصة بمفـــده البحــث الاساســيه

• بناء اطر نظرية نختص بمؤشرات مفردات المدى المتاح للتغير و التبادلية للهوية (الثنكل و الخلفية بصريا).

• تطبيق الأطر النظرية على نتاج تخصصي التطبيقي واستخلاص النتائج ومناقتثنها وتحليلها بشكلين (أحادي وثثائي) التغيـر مــع

عرض النتائج والاستنتاجات.

1. - 1 الجزء الاول: الإطار المعرفي العام

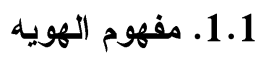

1.1.1 التهوية - التعريفات

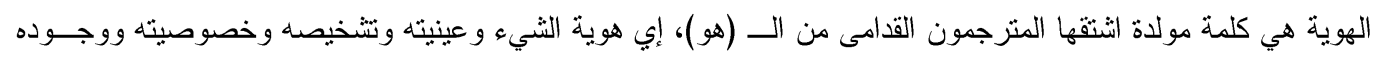

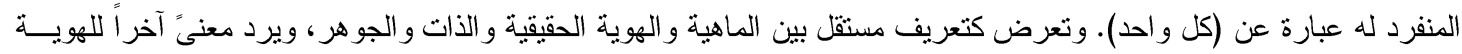

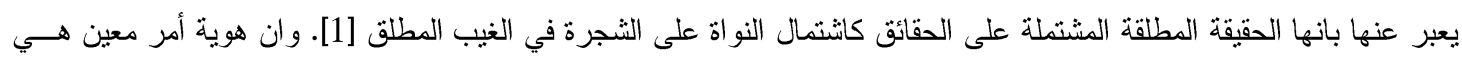

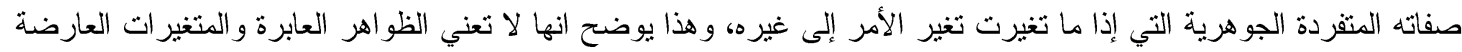

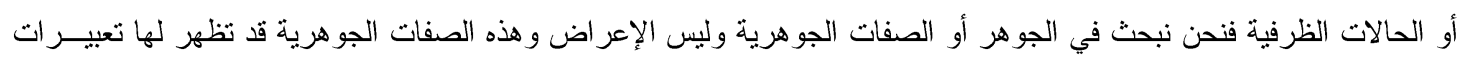

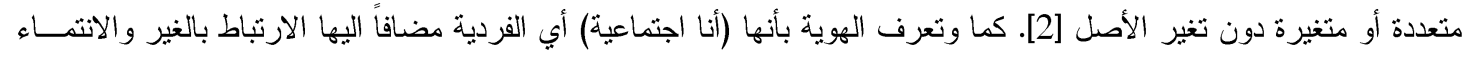

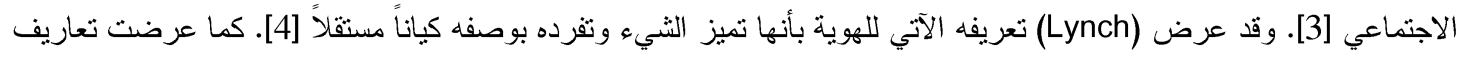

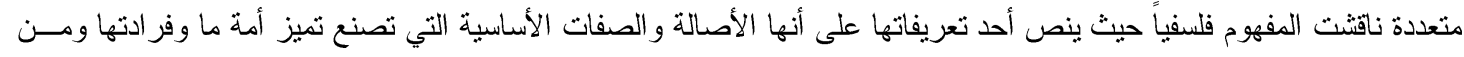

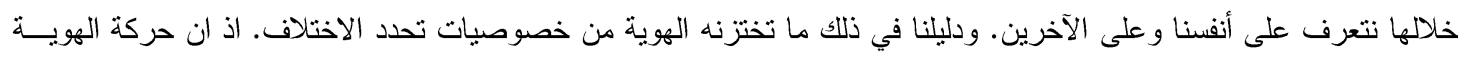

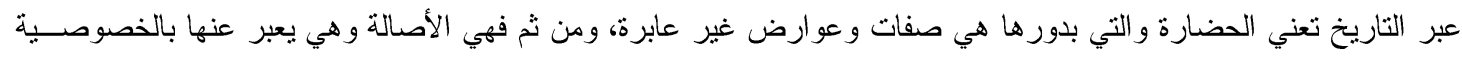

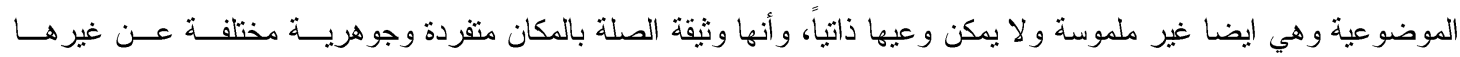

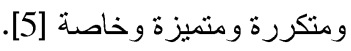

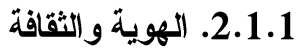

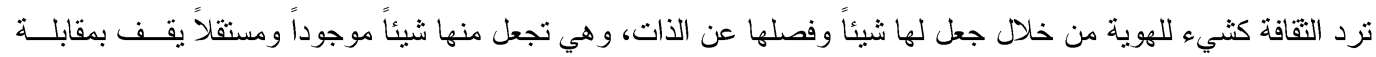

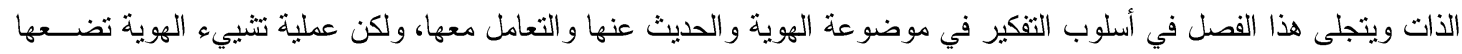

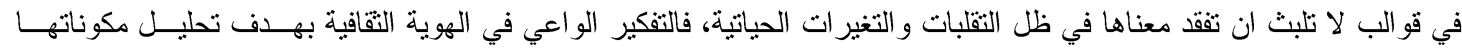

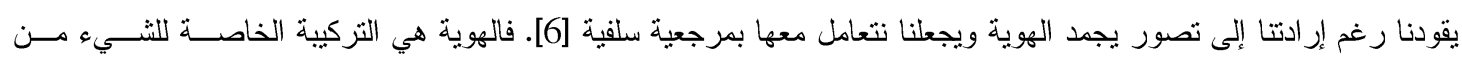

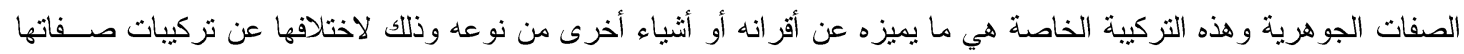

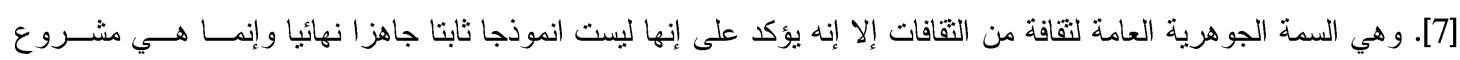

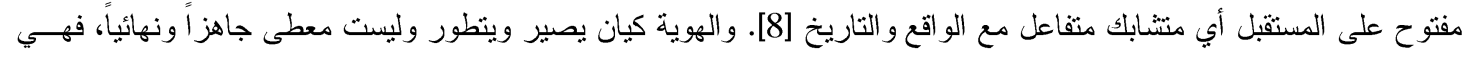

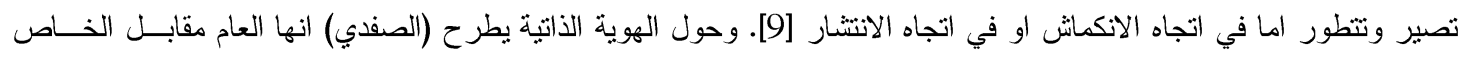

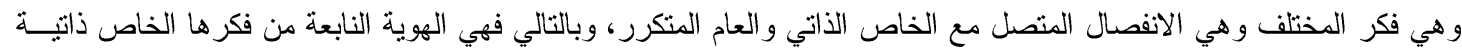

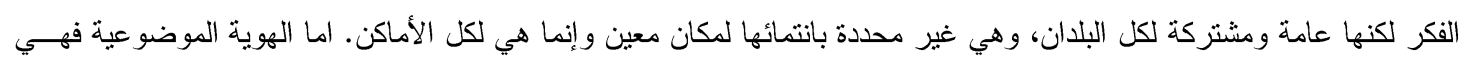

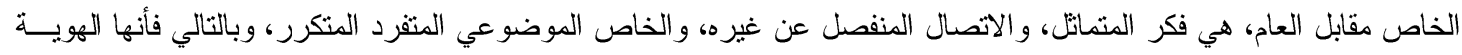

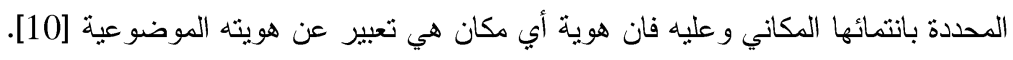




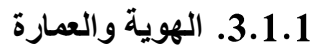

يشير (الجادرجي) إلى الهوية كفهوم مثلبور في العمارة من خلال الثنكل وخصائصد والهوية الكلية مفهوم مرتبط بالعمارة

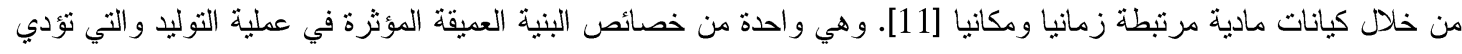

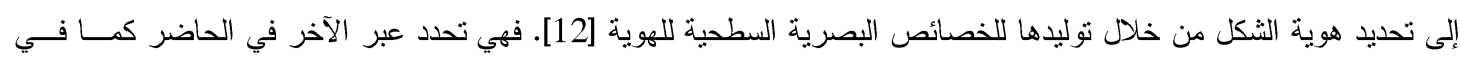

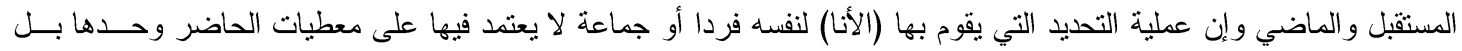

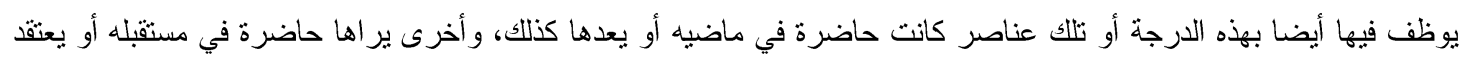

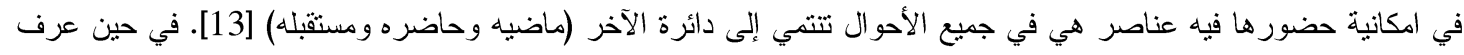
(Abel)

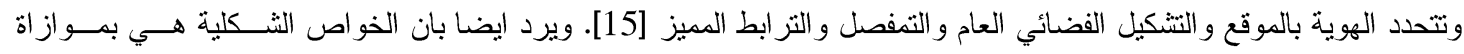

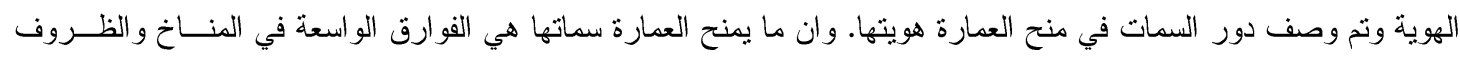

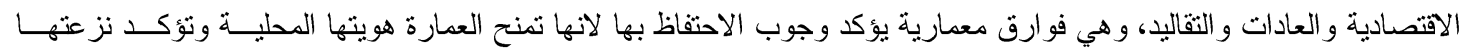

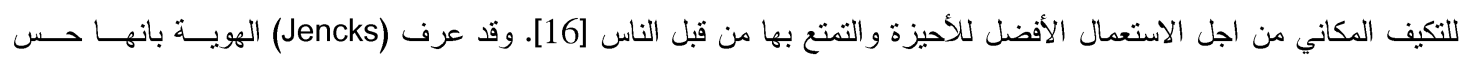

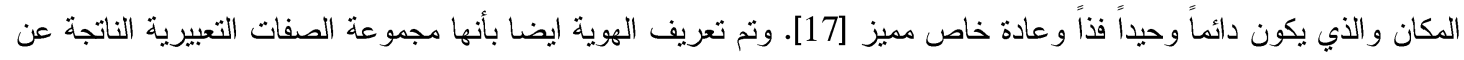

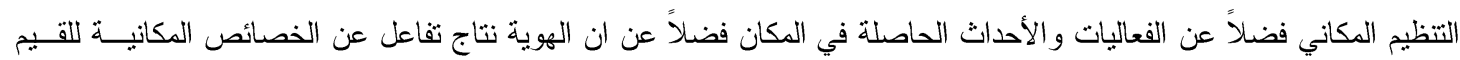

الإنسانية [18].

\subsection{1 الهوية - تصنيفات عامة}

$$
\text { 1. ويستتد (Correa) على ثلاثة أسس لفهم ماهية الهوية في العمارة وهي: - }
$$

• الهوية عبارة عن سلسلة عمليات متتابعة وليست شيئًا جامداً ثابتاً وهي تتحول مع الزمن لذا تكون دينامية الحركة. •وطالماً ان الهوية تتئكل من سلسلة من العمليات لذلك لا يمكن (فبركتها) فنحن نطور هويتتا من خلال تعاملنا مع ما ندركه مسن حولنا.

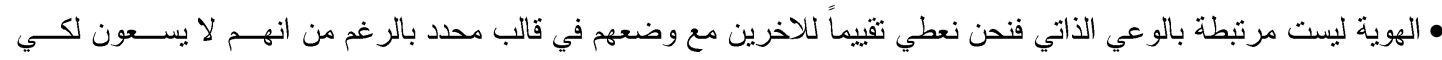

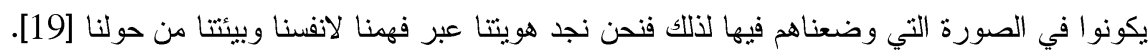
2. أما (تركي الحمــد) فانه يميّز بين (الهوية المقسة) و (الهوية العملية) ......

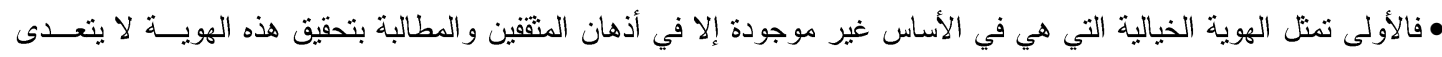

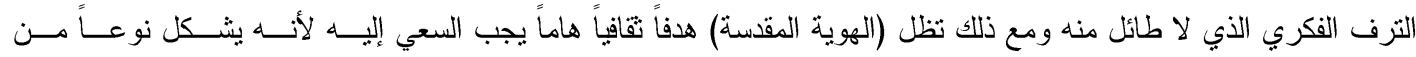
المرجعية الثقافية والتاريخية التي توحد بين الجماعة الكبيرة التي تحتوي في داخلها جماعات أخرى أصغر منها.

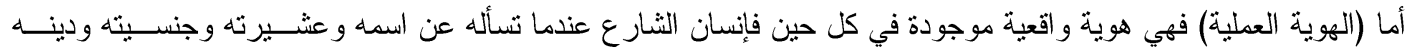

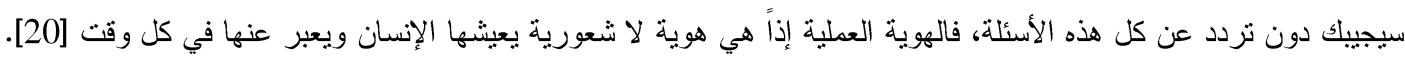
3. ويمكن ان نميز بين نوعين من التحو لات للهوية المعمارية في البيئة الحضرية: -

• النحو لات الداخليه: وهي التي تحدث داخل بنية الهوية من خلال تطور هذه البنية وفهمها عبر الاتثكال الفيزيائية داخـلـل الييئسة

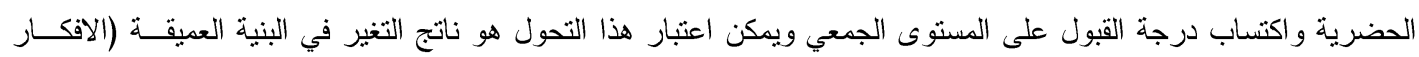

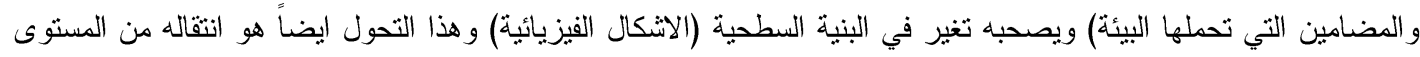
الفردي إلى المستوى الجمعي. • التحو لات الخارجيه: وتحدث من خلال نأثير التيارات الفكرية (المعمارية) على شكل طر از وأنماط جديدة تدخل على البنية وهي

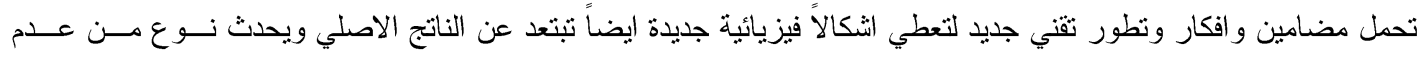


الوضوح وصعوبة الادر اكك لمثل هذا النتاج بسبب عدم وجود نوع من التفاعل بينه وبين بنية الييئة الحضرية ويمكـن ان يفسـر على انه عدم التقارب بين المستوى العميق للبنية الحضرية و البعد السطحية الجديدة [21].

بعد ان تم عرض المعزفه المتتو عه عن مفرده البحث الاساسيه وهي مفرده الهويه وتوضيح الاطر العامه لها والذي سـيقود التها

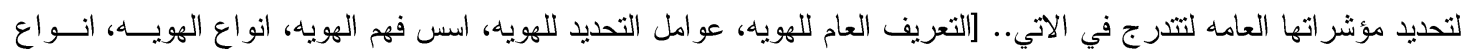

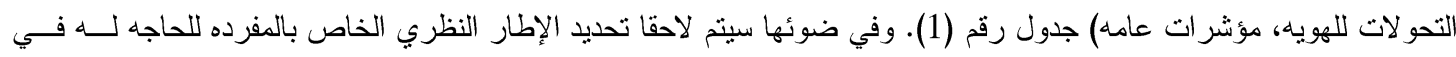

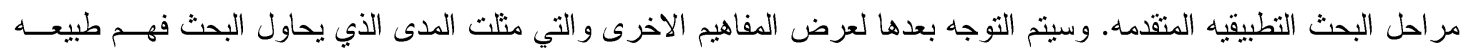

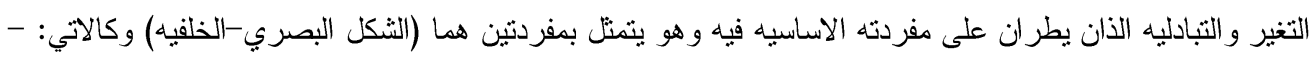

جدول رقم (1) يوضح الإطار النظري لمفهوم الهويه/ (اعداد: الباحثين).

\begin{tabular}{|c|c|c|c|}
\hline 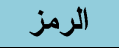 & القيم الممكنه & المفرده الثاتويه & المفرده الرئيسيه \\
\hline X.1.1 & خصوصيه الثيء ووجوده المنفرد & \multirow[t]{11}{*}{ التعريف العام للهويه } & \multirow[t]{26}{*}{ الهويـه } \\
\hline $\mathrm{X.1.2}$ & | ماهيه الثيء & & \\
\hline $\mathbf{X . 1 . 3}$ & 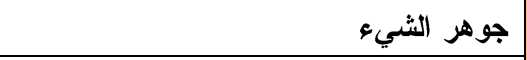 & & \\
\hline $\mathrm{X.1.4}$ & | الحقيقه المطلقه & & \\
\hline $\mathrm{X.1.5}$ & | صفات الثيء المتفرده الجوهريه & & \\
\hline $\mathrm{X.1.6}$ & الانا الفرديه والارتباط بالغير & & \\
\hline $\mathrm{X.1.7}$ & الاصاله و الصفات الاسـاسيه & & \\
\hline $\mathrm{X} .1 .8$ & مفهوم متبلور من خلال الثكل وخصائصه & & \\
\hline $\mathrm{X.1.9}$ & امتلاك العماره لجوهر خاص & & \\
\hline$X .1 .10$ & حسن المكان & & \\
\hline$X .1 .11$ & الصفات التعبيريه الناتجه عن التظظيم المكاني & & \\
\hline $\mathrm{X.2.1}$ & التكوينات والبنى الشكليه & \multirow{4}{*}{ عوامل التحديد للهويه } & \\
\hline $\mathrm{X.2.2}$ & الظروف الموقعيه & & \\
\hline $\mathrm{X.2.3}$ & ا التشكيل الفضائي العام & & \\
\hline $\mathrm{X.2.4}$ & التمفصل والتر ابط المتميز & & \\
\hline X.3.1 & سلسله عمليات متتابعه & \multirow[t]{3}{*}{ اسس فهم الهويه } & \\
\hline $\mathbf{X . 3 . 2}$ & تطور من خلال التعامل & & \\
\hline $\mathbf{X . 3 . 3}$ & غير مرتبطه بالوعي الذاتي & & \\
\hline $\mathrm{X.4.1}$ & الهويه المقدسه & \multirow[t]{2}{*}{ انواع الهويه } & \\
\hline$X .4 .2$ & الهويه العمليه & & \\
\hline $\mathbf{X . 5 . 1}$ & التحولات الداخليه & \multirow{2}{*}{$\begin{array}{r}\text { لاتواع التحولات } \\
\text { لاتويسه }\end{array}$} & \\
\hline X.5.2 & التحولات الخارجيه & & \\
\hline $\mathrm{X.6.1}$ & الهويه مطلب عام واساسي & \multirow[t]{4}{*}{ مؤشر ات عامه } & \\
\hline $\mathrm{X.6.2}$ & الهويه والاتتماء & & \\
\hline$X .6 .3$ & الهويه والاحساس بالمكان & & \\
\hline X.6.4 & الهويه والمعنى & & \\
\hline
\end{tabular}




\section{1 المفردات الخاصة بالمدى المعرفي المتاح للتغير والتبادلية

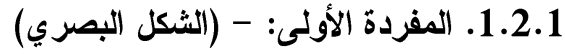

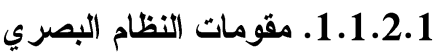

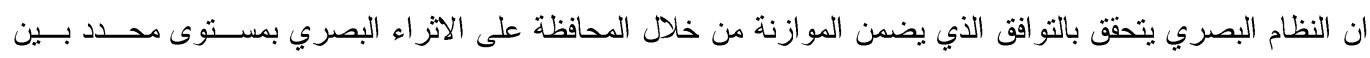

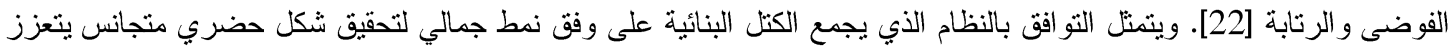

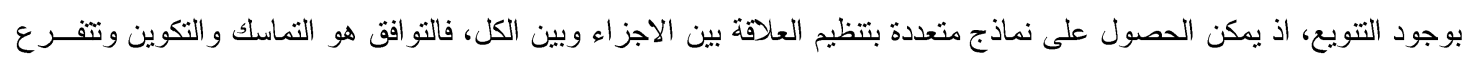

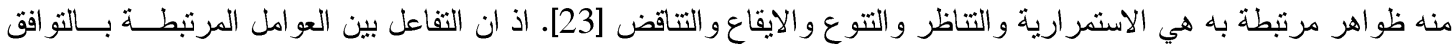

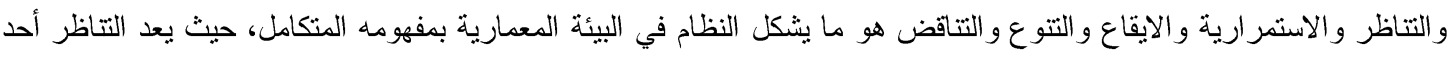

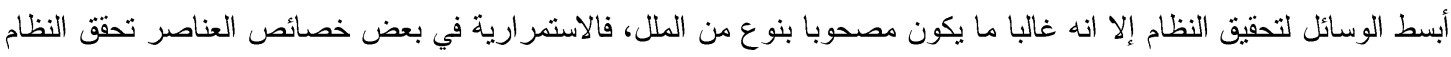

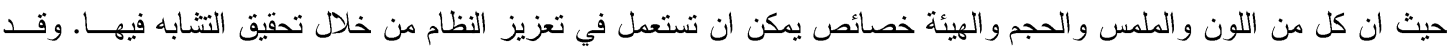

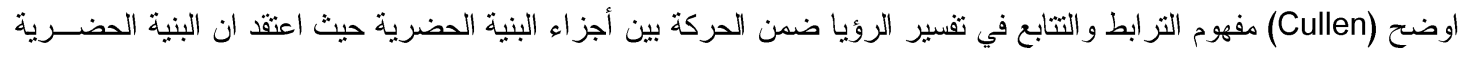

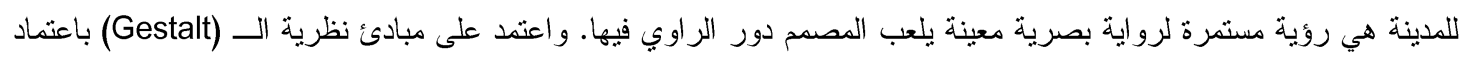
مفردني (الملمس - الحافة) و التي تمكن الاحساس بالعلاقة بين (الثكل - المجال) [24].

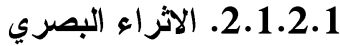

الاثر اء البصري بسهم في تجربة حسية فضائية متكاملة تجسدالاحساس بالهوية والاتماء المكاني وتحقق مستويات عالية من

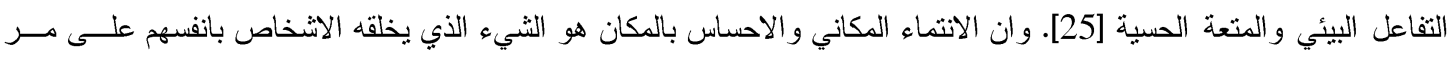

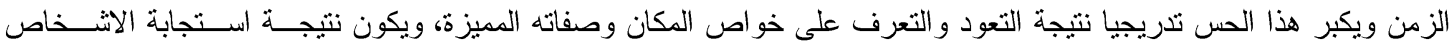

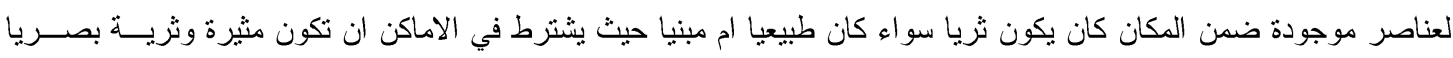

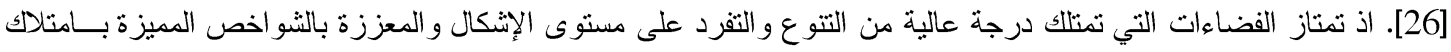

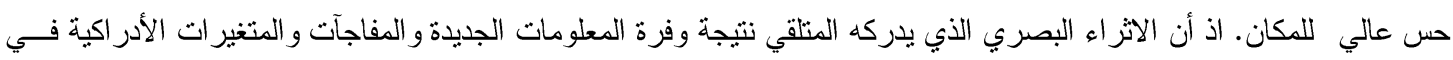

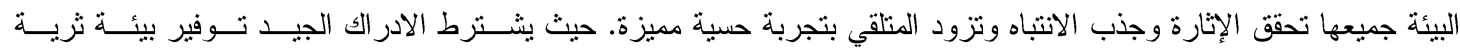

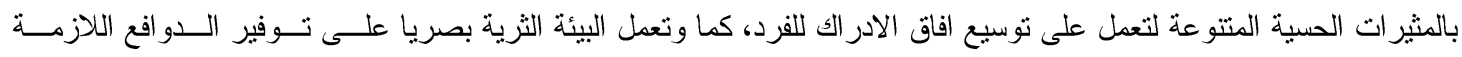

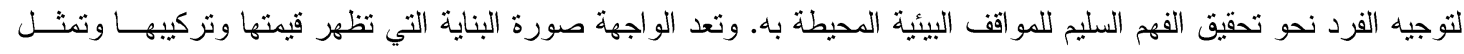

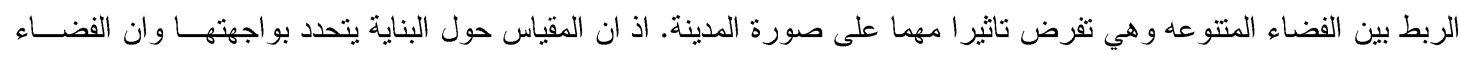

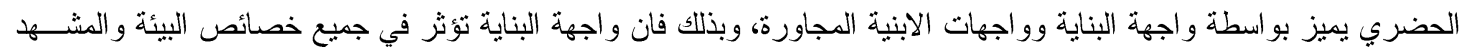

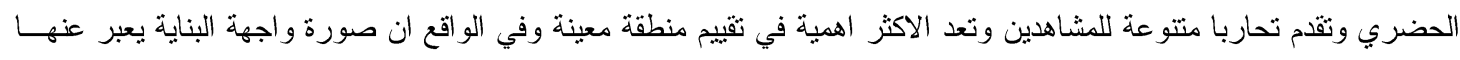

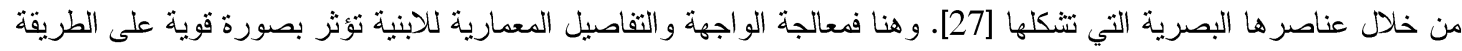

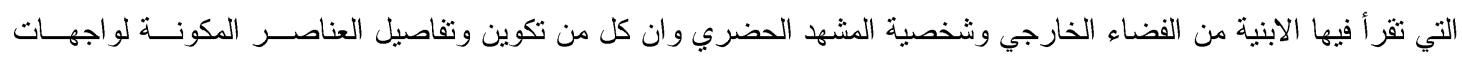
الابنية له تاثثير ايضا على الكتلة والمقياس الظاهر للابنية [28].

吕.1.2.1 العنصر المادي وتاسيس الثكل البصري

يعد الثنكل المبني الدال وما يخلقه من دلالات موضعية (دينية، اجتماعبة، تعبيرية) والعاكسة لمفاهيم (القدرة، البيئـة، ....

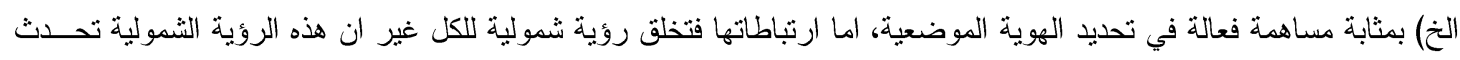

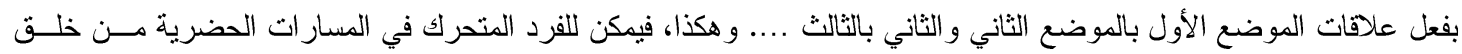

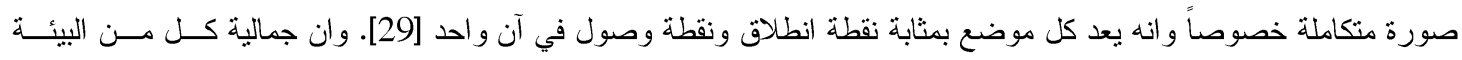

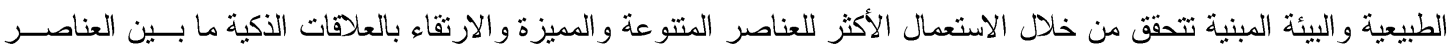

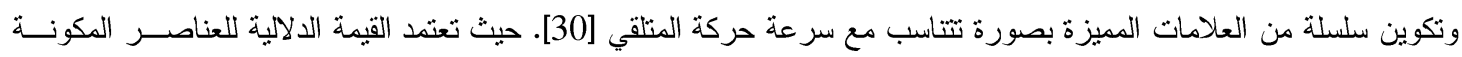

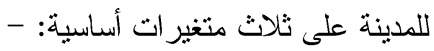


أولا: طبيعة الدور الوظيفي.

ثانباً: التعبيرية الثنكلية.

ثالثاً: طبيعة العلاقة الترابطية مع عناصر المنظومة الاخرى وترتيبها في الصورة الكلية [31].

وان اعتماد ما يشكل جزءاً من الصورة الكلية وعقدة في الثبكة الحضرية للمدينــة علــى مسـتوى العلاقـات البصــرية

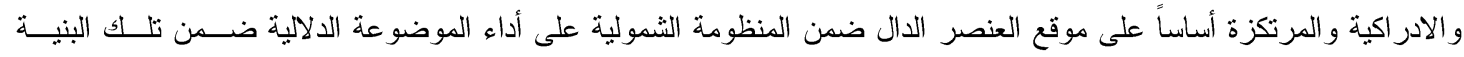
الثمولية للمنظومة [32]. وإن للعناصر المعمارية القدرة على التعبير عن معنى وقيم الحضار ات و الثتعوب و الثقافات المختلفة، فهي

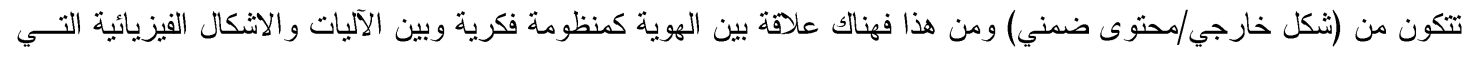
تنتباها الجماعات البثرية للتعبير عن هذه الهوية، اذ لا يمكن إدراك الأمور وفهمها دون التعبير عنها [33ن].

4.1.2.1. إدراك الثكل البصري من منظور العباق (علاقة المبنى بمجاوراته)

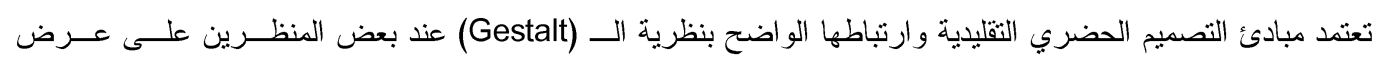

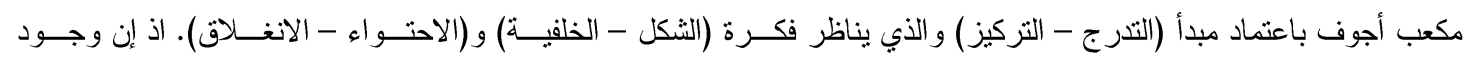

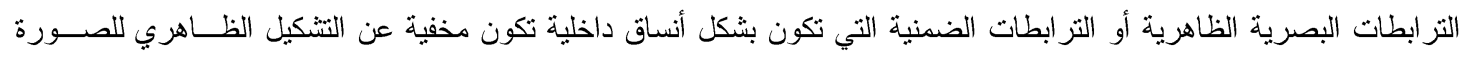

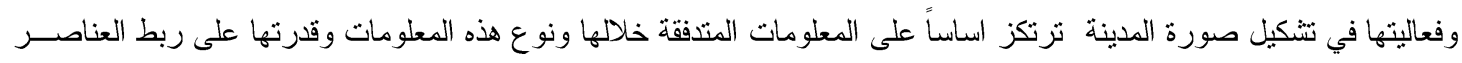

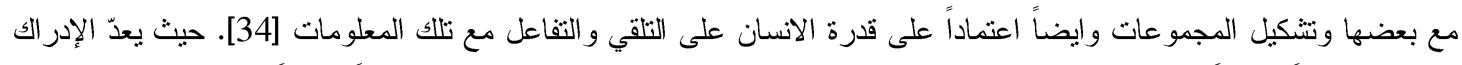

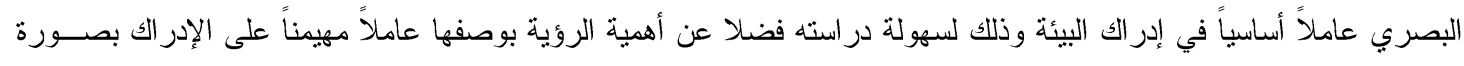

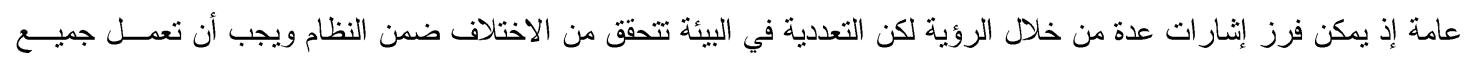

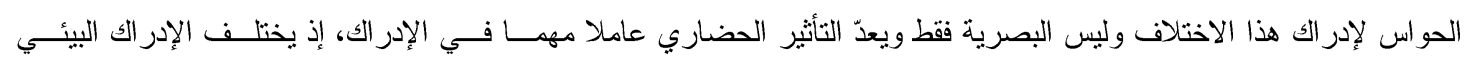

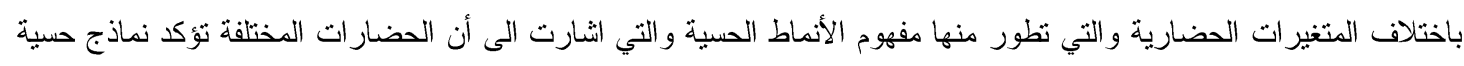

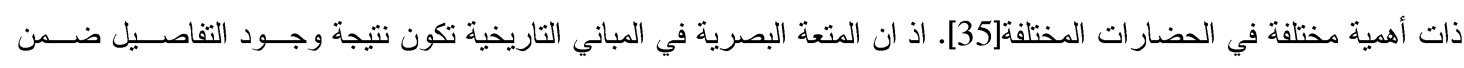

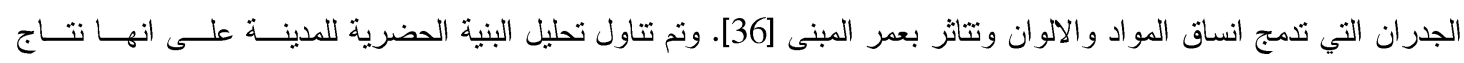

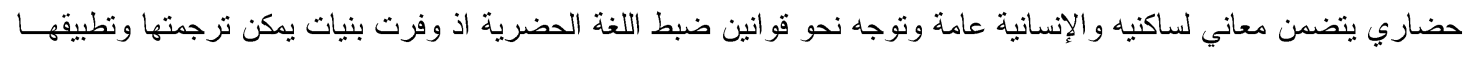

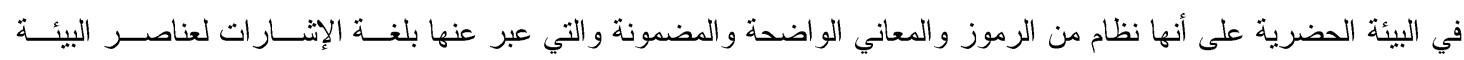
الحضرية من خلال البنية التركيبية ودر اسة معاني الاشار ات في علم الإثار ات. مع اختبار المدينة كنظام رسائل نســاعد الســاكنين

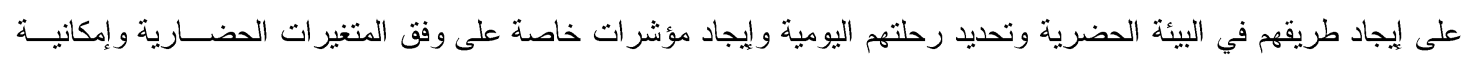
التداخل بين هذه المستويات وتقاطعاتها على وفق الاتفاق الجمعي وربط نظام الدلالات بالخصائص الفضائية [37].

2.2.1

1.2.2.1 ألصوره العامة للمدينة

تثدفق المعلومات البصرية في التز ابطات الظاهرية في الثبكة الحضرية للمدينة مكونة شكلا يطلق عليـهـه صــورة المدينـة

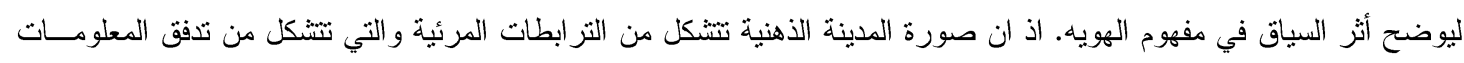

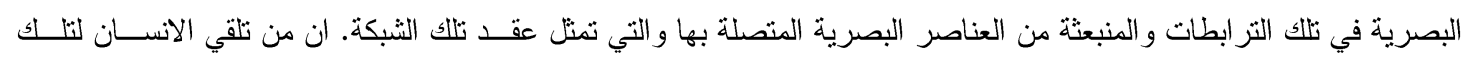
المعلومات و التفاعل معها تتتكل لديه الصورة البصرية الفردية والتي يكون جزء هنها منها مشتركا بين المجموعة البشرية في تلك البيئة الحضرية ومن تداخلها تتكون الصورة الكلية للمدينة [38]. حيث يبدو ان لكل مدينة صورة عامة هي مجموعة متداخلة من صــور مفردة أو قد تكون هناك سلسلة من الصور كل واحدة منها لدى عدد معين من سكانها فهذه الصور التي تكونت لاى تلاك الجماعـات

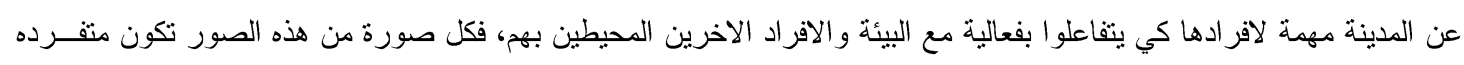

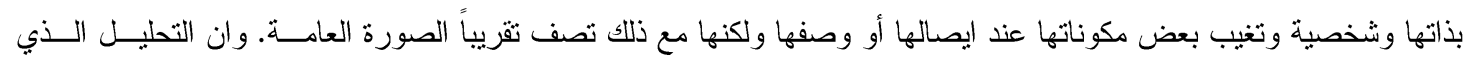

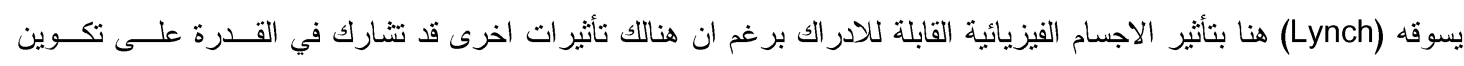
الصورة و التي تكون متمثلة بالمعنى الاجتماعي لمنطقة معينة أو الوظائف التي تقدمها او تاريخ تلك المنطقة وحتى اســمها احيانـاً، 
لكن اهتمامه هنا بتركز نحو دور الثكل نفسه في تتنكيل صورة المدينة، ققبل معرفة عناصر صورة المدنية لابد من التأكيد على أن

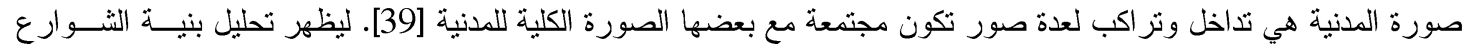

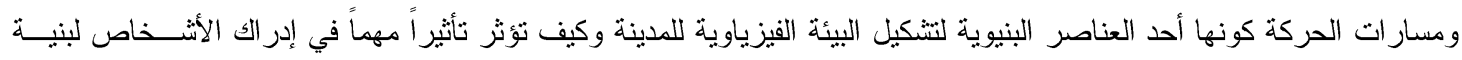

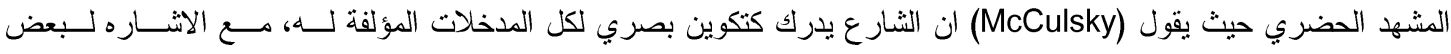

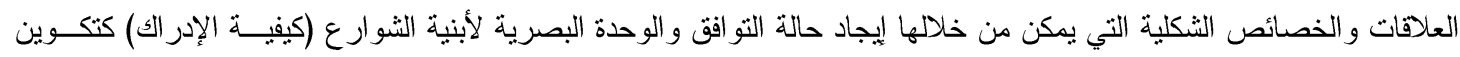

متماسك [40].

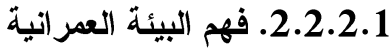

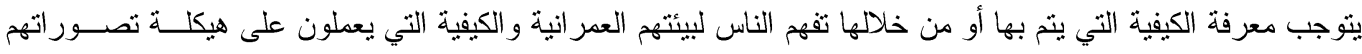

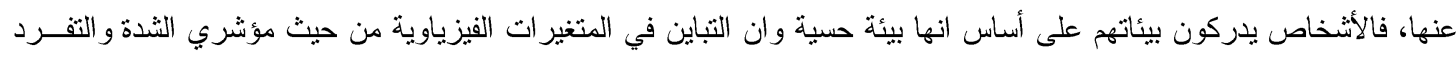

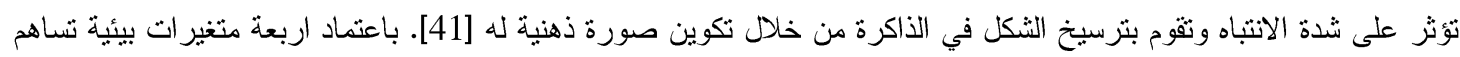

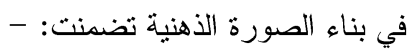

قدرة التصور .

وضوحية الثكل.

محيط سلوك الفعل الثخصي.

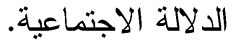

ان كل موضو عة من هذه الموضو عات وبفضل دلالاته الاينية والاجتماعية و التعبيرية تسهم في رسم صورة دلاليــة عامــة

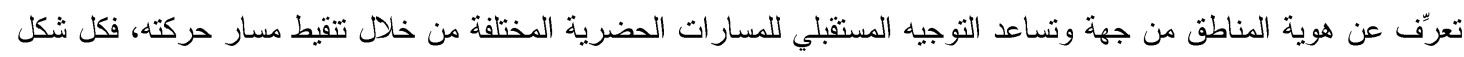

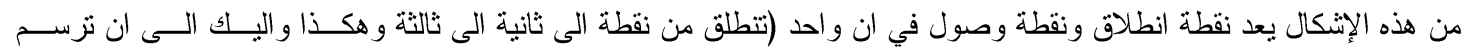

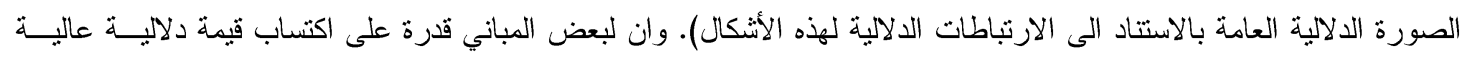

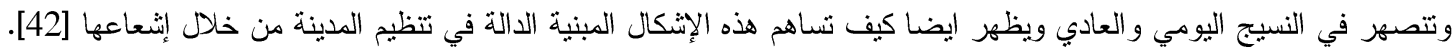

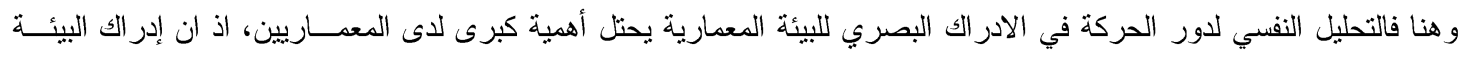

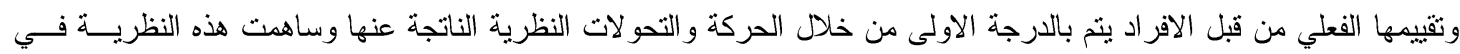

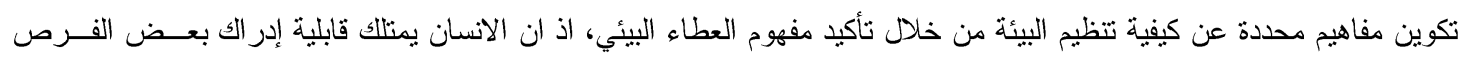

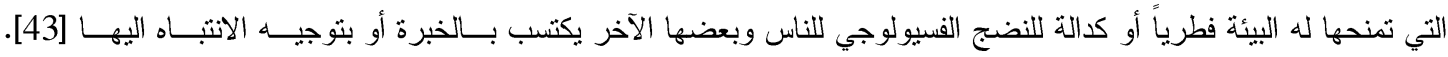

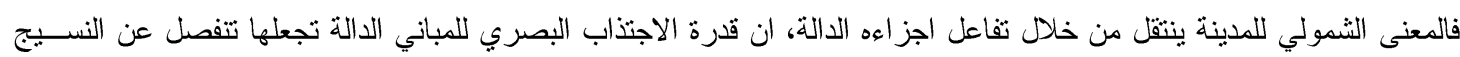

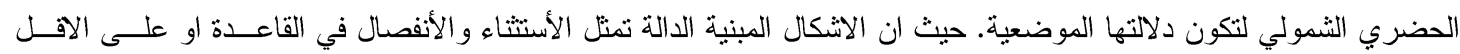

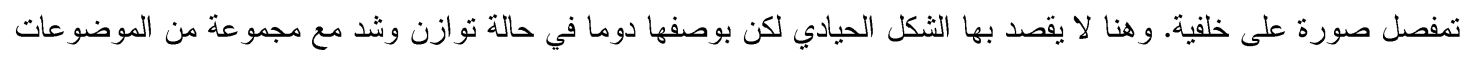

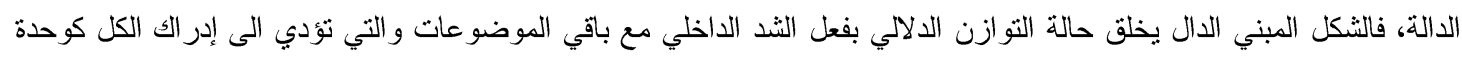

غير قابلة للانفصال [44].

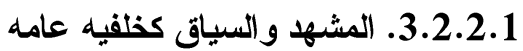

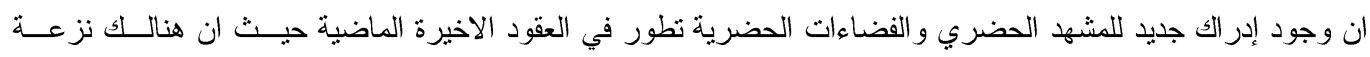

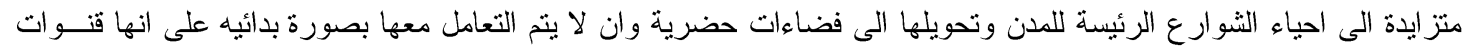

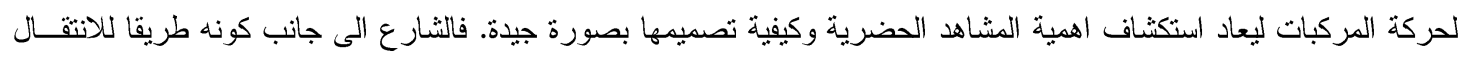

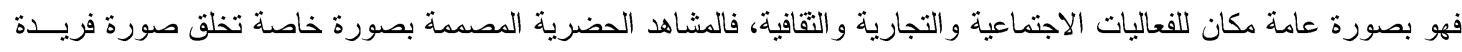

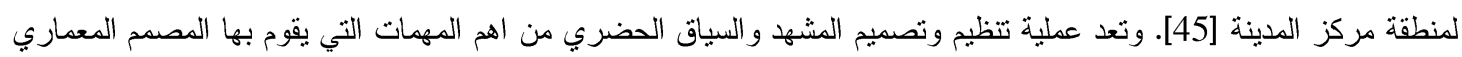

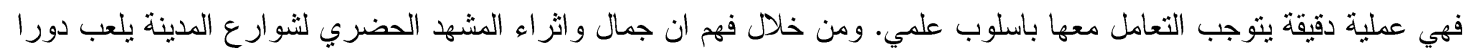

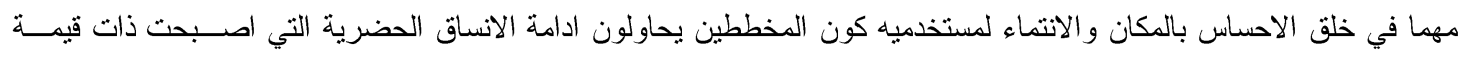


عالية لدى المجتمع [46]. لذلك يجب القيام بدر اسات توفر اساسا لمعرفة حقيقية لتحسين المشهد الحضري خلال دليل تصميمي كون

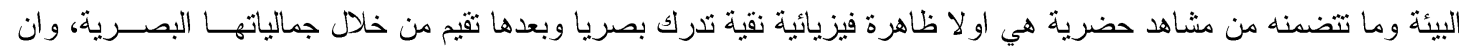

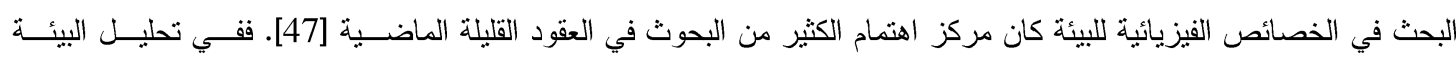

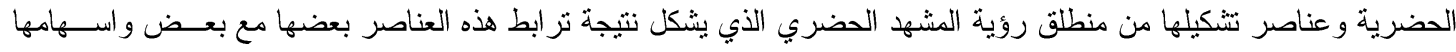

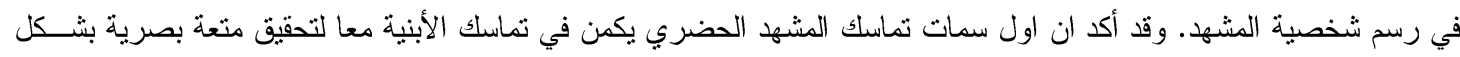

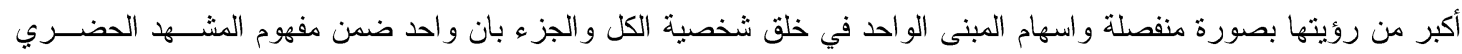

المتماسك [48].

\subsubsection{1 العلاقة العامة للخفية مع عناصرها}

نادت الطروحات بالاهتمام بالسياق كمحاولة لربط البناية مع مجاور اتها بعلاقات على جميع المستويات بعد فثــل سـابقاتها

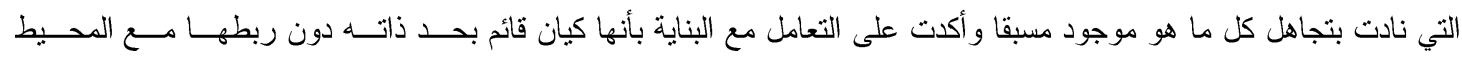

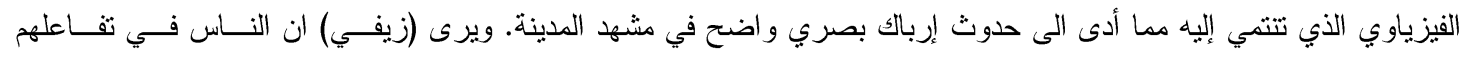

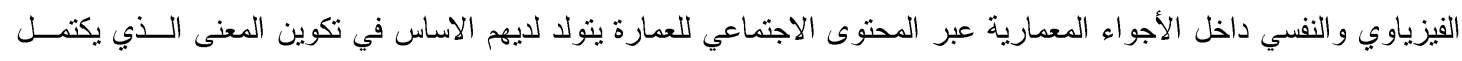

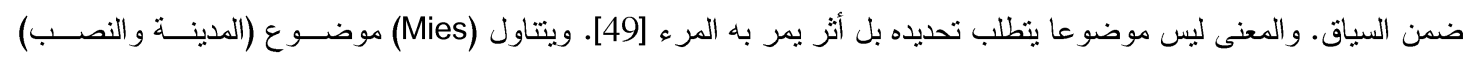

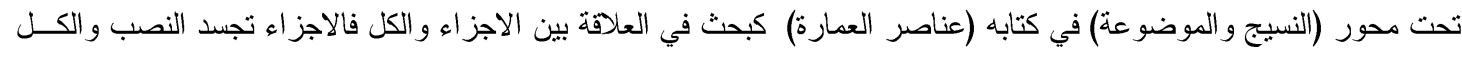

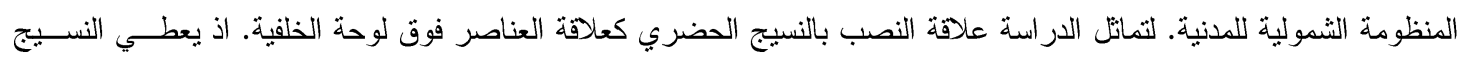

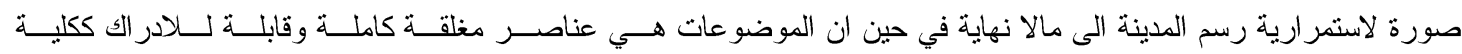

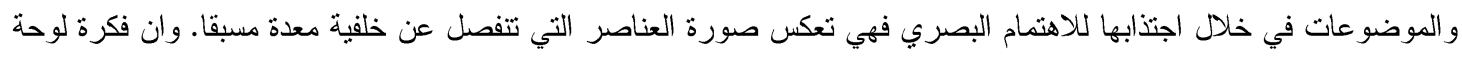

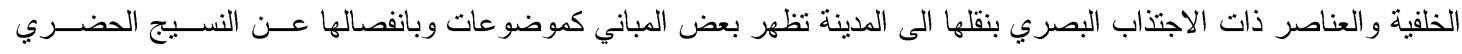

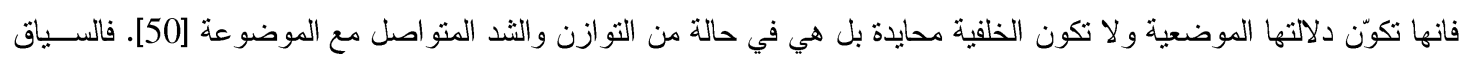

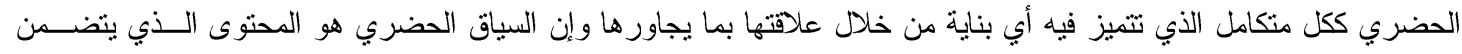

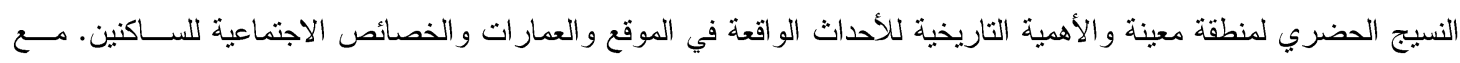

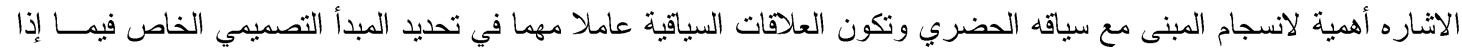

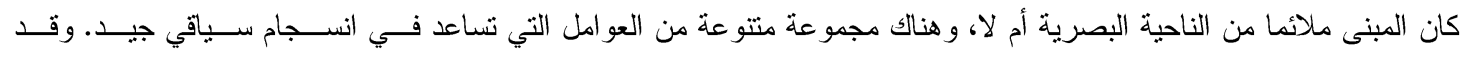

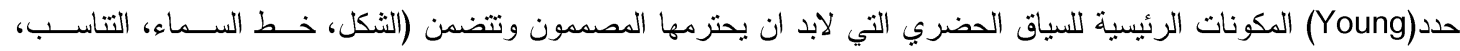
الوحده، التوازن، المقياس، اللون، التفصيل، الملمس، النموذج، تحديد الموقع المناسب، التكتيل، الايقاع، المواد) [51].

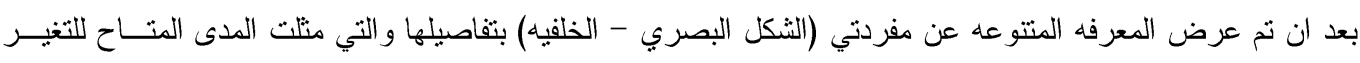

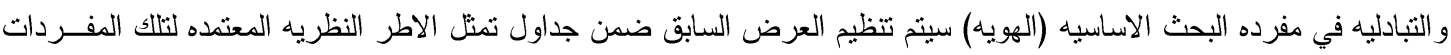

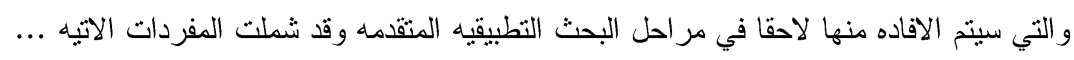

الثكل البصري (التثو افق البصري، التزابط و التتابع البصري، الادر الك البصري، التنعه البصريه، القيمه الدلاليه للعناصـر ).

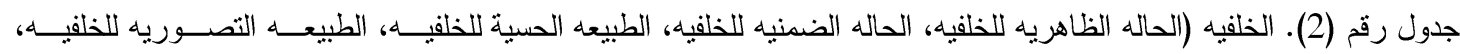
عو امل ومكونات السياق). جدول رقم (3). 2. - 2 - الجزء الثاني: الجاتب التطبيقي

1.2.

توضح فيما سبق في الجزء الاول عرض المفاهيم العامه للبحث و على شكل جز اين اختص الاول بمفاهيم البحث الاساسـيـه

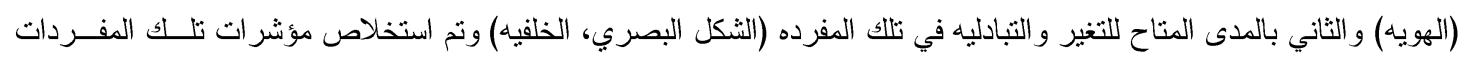

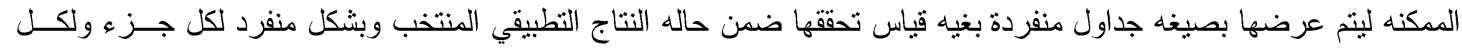

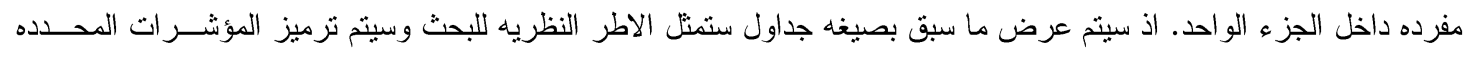


ضمنها وقياس التحقق لها (اختصار اللخطوات) وعرض نتائج ذلك التحقق بشكل ارقام، حيث ســـيمثل الجـدول (4) و (5) الاطـــر النظريه ليفاهيم (الثنكل البصري، الخلفيه) ومؤشر اتهما الخاصه.

وسيتم كذلك عرض المعرفه العامه عن النموذج النطييقي المنتخب و الذي سيمثل حاله مفهوم البحث الاســاس بعـــ قيــاس

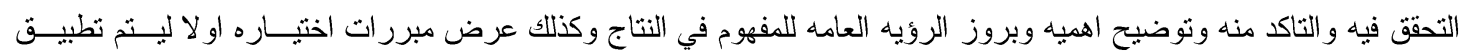
مؤشرات الاطر النظريه الاخرى عليه وقياس نحققها فيه ومن ثم التوجه لـقارنه نتائج ذلك النحقق بين الاطارين بقصد فهم التـاثير التفصيلي و المدى المتاح للتغير و التبادليه بين الدفهومين.

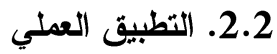

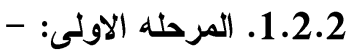

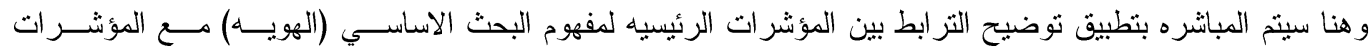

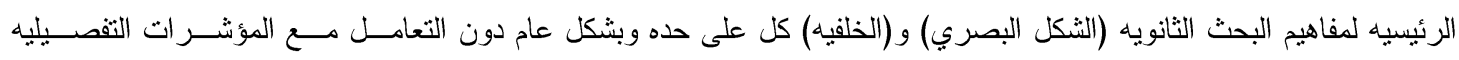

للمفاهيم اختصار اللوقت و الجهد بالنظر للالاله الو اضحه للمؤشر ات العامه لكل المفاهيم المثنباه عن طبيعتها العامه وكما يلي: -

جدول رقم (2) يوضح ترابط مفهوم الهويه مع مفهوم الثكل البصري / (اعداد:الباحثين).

\begin{tabular}{|c|c|c|c|c|c|c|c|c|}
\hline \multicolumn{2}{|c|}{ المجموع } & القبيمه الثلالايه للعناصر & المتعه البصريه & |الادر الك البصري & الترز ابط و التبتابع & |التكوافق البصري| & الثنكل البصري & الهوية \\
\hline \multicolumn{2}{|c|}{2} & 0 & & & & 0 & \multicolumn{2}{|c|}{ التعريف العام للهويه } \\
\hline \multicolumn{2}{|c|}{3} & 0 & & 0 & 0 & & \multicolumn{2}{|c|}{ عوامل التحديا للهويد } \\
\hline \multicolumn{2}{|c|}{3} & 0 & & 0 & & 0 & \multicolumn{2}{|c|}{ اسس فهم الهوية } \\
\hline \multicolumn{2}{|c|}{3} & & 0 & 0 & & 0 & \multicolumn{2}{|c|}{ انواع الهوية } \\
\hline \multicolumn{2}{|c|}{3} & & 0 & 0 & 0 & & \multicolumn{2}{|c|}{ انواع التحولات للهويد } \\
\hline \multicolumn{2}{|c|}{4} & 0 & 0 & & 0 & o & \multicolumn{2}{|c|}{ مؤشرات عامه } \\
\hline 18 & 18 & 4 & 3 & 4 & 3 & 4 & 30 q & 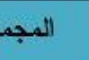 \\
\hline
\end{tabular}

جدول رقم (3) يوضح ترابط مفهوم الهويه مع مفهوم الخلفيه / (اعداد: الباحثين).

\begin{tabular}{|c|c|c|c|c|c|c|c|c|}
\hline & 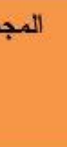 & عوامل ومكونات & 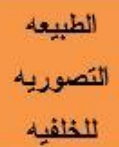 & الطيبعه الحسيه & اللالثة الضمنيه & الحاله الظاهريه & الخلفيه & الهويد \\
\hline & 3 & & 0 & 0 & & 0 & \multicolumn{2}{|c|}{ التُعريف العام } \\
\hline & 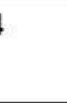 & 0 & 0 & 0 & 0 & & \multicolumn{2}{|c|}{ عوامل التحبيد } \\
\hline & 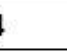 & 0 & & 0 & 0 & 0 & \multicolumn{2}{|c|}{ اسس فهم الهويه } \\
\hline & 1 & & 0 & 0 & 0 & 0 & \multicolumn{2}{|c|}{ انواع الثهويه } \\
\hline & 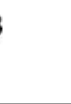 & 0 & 0 & 0 & & & \multicolumn{2}{|c|}{ التواع التحولات } \\
\hline & & 0 & 0 & & 0 & & \multicolumn{2}{|c|}{ مؤشر ات عامه } \\
\hline 21 & 21 & 4 & 5 & 5 & 4 & 3 & 30 & المجمو. \\
\hline
\end{tabular}




$$
\begin{aligned}
& \text { 2.2.2. عرض وتحليل ومناقثه النتائج - (المرحله الاولى): - } \\
& \text { 1.2.2.2 التحليل الاحادي التغير } \\
& \text { 1. نتائج الترابط بين مؤشرات مفردني (الهويه - الثكل البصري) } \\
& \text { • التعريف العام }
\end{aligned}
$$$$
\text { سجلت النتائج تحقق حالات عدد (2) حاله لكل من المؤشرات الاتيه (التو افق البصري، القيمه الدلاليه للعناصر). }
$$$$
\text { • موامل التحديد للهويه }
$$

سجلت النتائج تحقق حالات عدد (3) حالات لكل من المؤشر ات الاتيه (التزر ابط و التتابع البصري، الادر الك البصري، القيمـــ

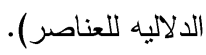

$$
\text { • اسس فهم الهويه }
$$

سجلت النتائج تحقق حالات عدد (3) حالات لكل من المؤشرات الاتيه (التو افق البصري، الادر اك البصري، القيمه الدلاليـهـ.

سجلت النتائج تحقق حالات عدد (3) حالات لكل من المؤشرات الاتيـــهـ (النتو افـق البصــري، الادر الك البصـرب، المتعــه

البصريه).

$$
\text { • انواع التحولات للهويه }
$$

سجلت النتائج نحقق حالات عدد (3) حالات لكل من المؤشرات الاتيه (الترابط والتتابع البصري، الادرالك البصري، المتعه

$$
\text { البصريد). }
$$

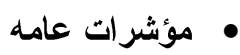

سجلت النتائج نحقق حالات عدد (4) حالات لكل من المؤشر ات الاتيه (التو افق البصرب، التزرابط و التتابع البصري، الدتعـه

البصريه، القيمه الدلاليه للعناصر).

2. نتائج التزابط بين مؤشرات مفردتي (الهويه - الخلقيه)

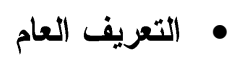

سجلت النتائج تحقق حالات عدد (3) حالات لكل من المؤشرات الاتيه (الحاله الظاهريه للخلفيه، الطبيعه الحسـية للخفيـه، الطيبعه التصوريه للخذفيه).

$$
\text { • عوامل التحديد للهويه }
$$

سجلت النتائج تحقق حالات عدد (4) حالات لكل من المؤشرات الاتيه (الحاله الضمنيه للذافيه، الطبيعه الحسـبة للخفيـه،

$$
\text { الطبيعه التصوريه للخلفيه، عوامل ومكونات السياق). }
$$

$$
\text { • اسس فهم الهويه }
$$

سجلت النتائج تحقق حالات عدد (4) حالات لكل من المؤشر ات الاتيه (الحاله الظاهريه للخفيه، الحاله الضــنيه للذافيـه،

$$
\text { الطييعه الحسية للخلفيه، عوامل ومكونات السياق). }
$$


سجلت النتائج تحقق حالات عدد (4) حالات لكل من المؤشرات الاتيه (الحاله الظاهريه للخلفيه، الحاله الضــنيه للخففيـه،

الطبيعه الحسية للخفيه، الطبيعه التصوريه للخلفيه).

$$
\text { • انواع التحولات للهويه }
$$

سجلت النتائج تحقق حالات عدد (3) حالات لكل من المؤشرات الاتيه (الطبيعه الحسية للخلفيه، الطبيعه التصوريه للخلفيـه،

عو امل ومكونات السياق).

• مؤشرات عامه

سجلت النتائج تحقق حالات عدد (3) حالات لكل من المؤشرات الاتيه (الحاله الضمنيه للخفيه، الطييعه التصوريه للخلفيـه،

عو امل ومكونات السياق).

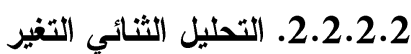

\section{1. نتائج الترابط بين مؤشرات مفردني (الهويه - الثكل البصري)}

سجلت النتائج تحقق حالات عدد (4) حالات لمؤشر (التو افق البصري) و (4) حالات لمؤشر (الترابط والتــابع البصــري)

و (4) حالات لمؤشر (الادراك البصري) و (4) حالات لمؤشر (المتعه البصريه) و (4) حالات لمؤشر (القيمه الدالاليه للعناصر).

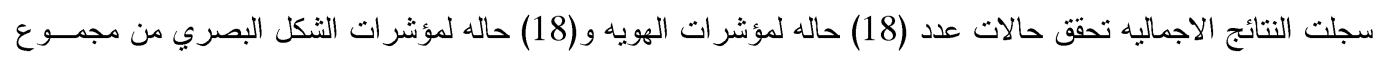

(30) حاله عامه مشتركه.

\section{2. نتائج الترابط بين مؤشرات مفردتي (الهويه - الخلفيه)}

سجلت النتائج نحقق حالات عدد (3) حالات لمؤشر (الحاله الظاهريه للخفيه) و (4) حالات لمؤشر (الحاله الضمنيه للخفيه)

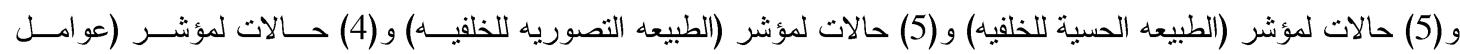

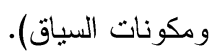

سجلت النتائج الاجماليه تحقق حالات عدد (21) حاله لمؤشر ات الهويه و (21) حاله لمؤشرات الخلفيه مسن مجمـوع (30)

حاله عامه مشتركه.

مناقشه

بعد ان تم اكمال المرحله الاولى من التطبيق العملي والتي اختصت بتوضيح حجم التحقق في الترابط بين كل من المؤشرات

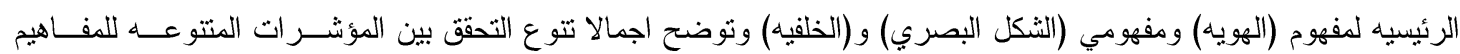

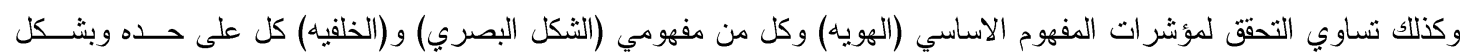
فارق بسيط بينهما عموما.

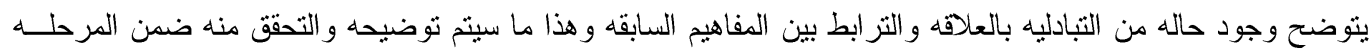

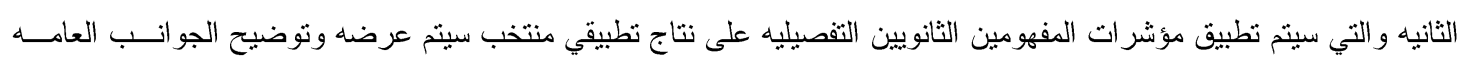
و التفصيليه له وكذلك مبرر ات اختياره ... وكالاتي: - 
3.2 النتاج المعماري المنتخب للتطبيق مشروع مبنى معهذ العالم العربي

(1.3.2 - مبررات اختيار المشروع

تعبير المشروع بفكرته الاساسيه عن تز ابط وتبادليه بين حضارتين بمكن ان تمثل احدهما شـــل و الاخــى خلفيه وبما يعزز فكره البحث الاساسيه. • تعالج الفكره الاساسيه ايضا مفهوم الثائيات المتتاقضه وربطها ببعض و هذا يخدم كذلك فكره البحث الاساسيه. •ترابط المشروع مع مقومات وعناصر طبيعيه في الموقع من جهه ومع سياق حضري لمدينه قديمه من جهه اخرى و وذا سيخدم جزء من هدف البحث الاساسيه. • يمثل المشروع تطور ا تقنيا وتكنلوجيا بارزا في اعاده احباء معالجات قديمه بشكل معاصر و هذه حاله تبادليه ايضـــ مكــن ان تخدم فكره وهدف البحث الاساسيه.

\subsection{2. مشروع مبنى معهد العالم العربي المعمار Jean Nounel - شرح المشروع}

يقيم المشروع حوارا بين حضارتين (الحضارة الغربية و الحضارة العربية) بين التاريخ و المعاصرة وكذلك بين منطقتهين

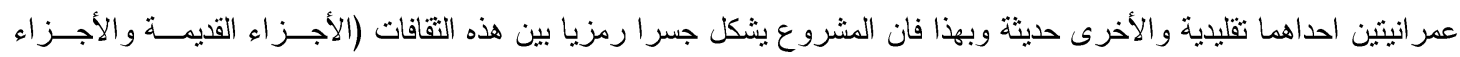

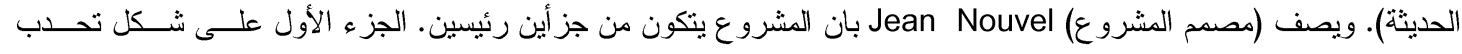

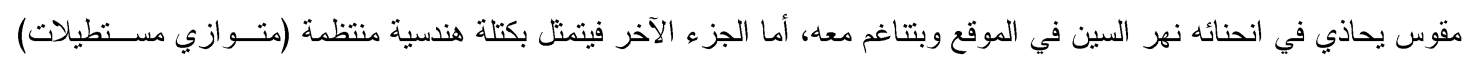

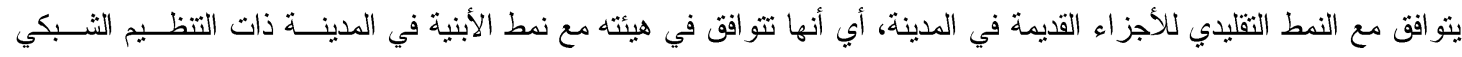

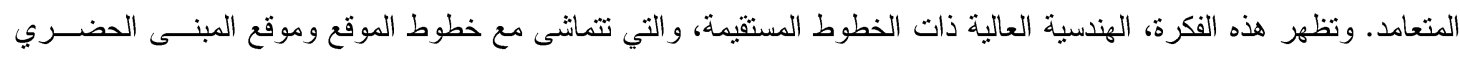

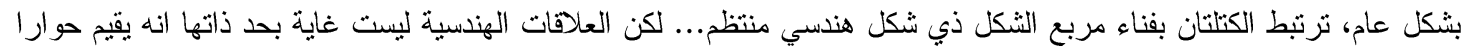

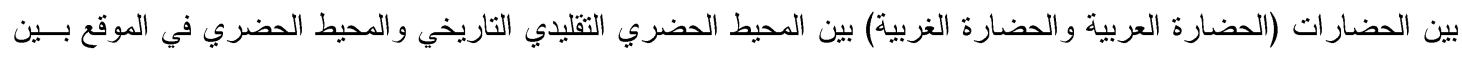

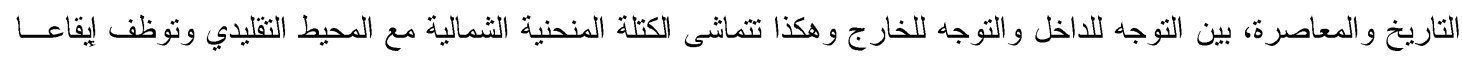

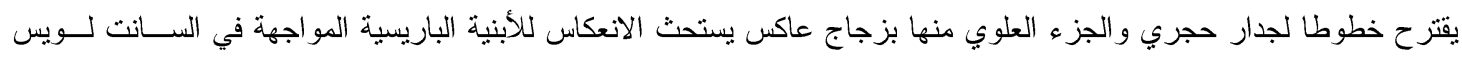
و الماريز وهنا تظهر العلاقات الهندسية المستعملة بأنها تعبير عن الربط بين الثنيئين.

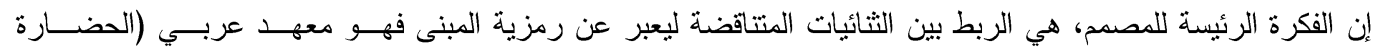

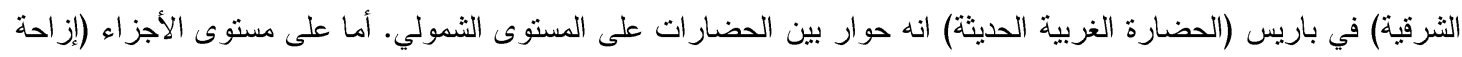

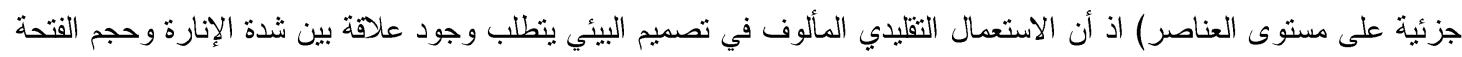

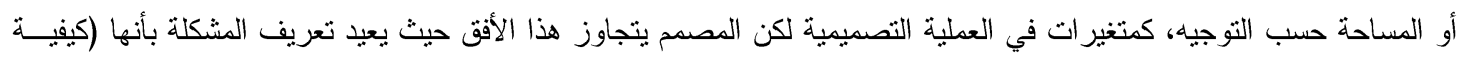

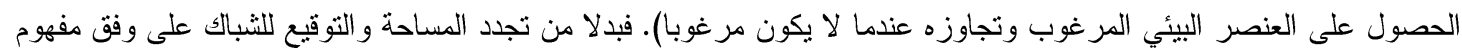

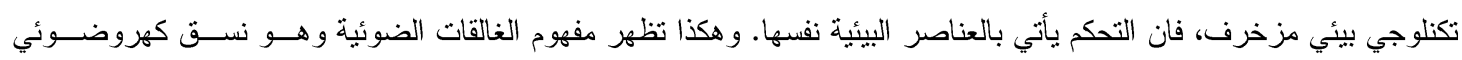

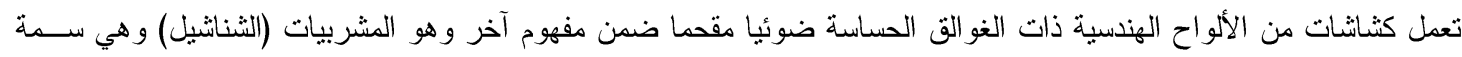

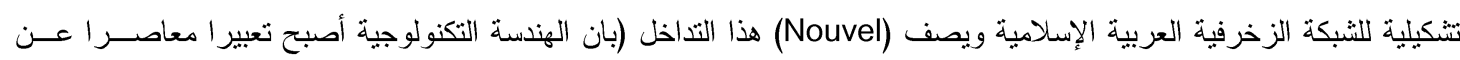

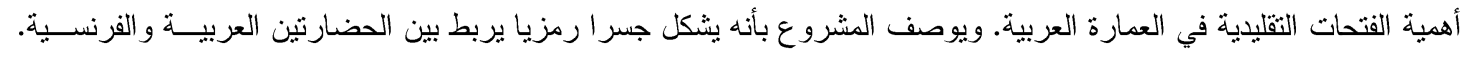

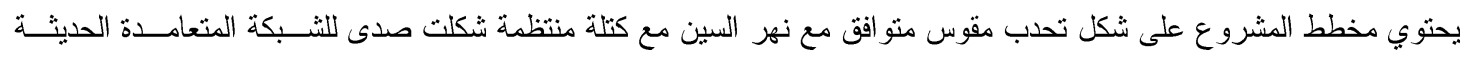
لللدينة وترتبط الكتلنان وتتنظمان حول فناء وسطي مفتوح تمثل مفاهيم العمارة العربية الإسلامية (52). شكل رقم (1).

و هنا سيتم تطبيق قياس تحقق مؤشرات الإطار النظري الخاص بالجزء الثناني وهو الددى المناح للتبادليه و المتعلق بمفردات

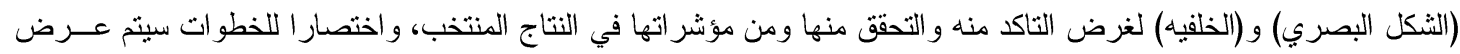
الإطار النظري وترميزهو وعرض النحقق للمؤشرات التفصيليه سويا في جدول واحد وكالاتي: - 
جدول رقم (4) يوضح الإطار النظري لمفهوم الثكل البصري / (اعداد: الباحثين).

\begin{tabular}{|c|c|c|c|c|}
\hline التحقق & 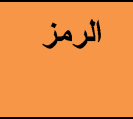 & المؤشرات & الثخانويه & الرئيسيه \\
\hline 0 & Y.1.1 & الموازنه & \multirow{11}{*}{ البصري } & 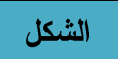 \\
\hline 0 & Y.1.2 & 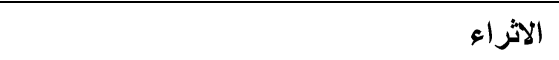 & & 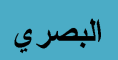 \\
\hline 0 & Y.1.3 & تجميع الكتل وفق نمط جمالي & & \\
\hline 0 & Y.1.4 & 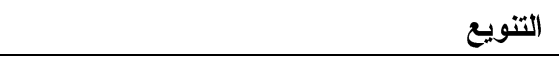 & & \\
\hline \multirow[t]{2}{*}{0} & Y.1.5 & تنظيم العلاقه بين الاجز اء و الكل & & \\
\hline & Y.1.6 & ا التماسك & & \\
\hline \multirow[t]{3}{*}{0} & Y.1.7 & الاستمر اريه & & \\
\hline & Y.1.8 & 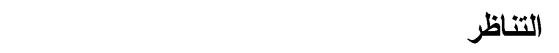 & & \\
\hline & Y.1.9 & 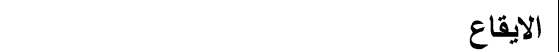 & & \\
\hline 0 & Y.1.10 & 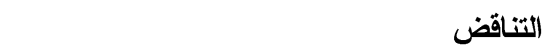 & & \\
\hline \multirow[t]{3}{*}{7} & 10 & المجموع & & \\
\hline & Y.2.1 & تفسير الروئا ضمن الحركه بين اجزاء البنيــه & \multirow{12}{*}{ البتر التتابع } & \\
\hline & & الحضريه & & \\
\hline 0 & Y.2.2 & ا الملمس / الحافه & & \\
\hline 0 & Y.2.3 & ا الثكل / المجال & & \\
\hline 0 & Y.2.4 & ا التشرج / التركيز & & \\
\hline \multirow[t]{2}{*}{0} & Y.2.5 & ا الثكل / الخظقيه & & \\
\hline & Y.2.6 & الاحتو اء / الاتغلاق & & \\
\hline 0 & Y.2.7 & شكل خارجي / محتوى ضمني & & \\
\hline \multirow[t]{2}{*}{0} & Y.2.8 & الترابطات البصريه الظاهريه & & \\
\hline & Y.2.9 & الترابطات البصريه الضمنيه & & \\
\hline 0 & Y.2.10 & الروئيه الدلاليه للعناصر & & \\
\hline 7 & 10 & المجموع & & \\
\hline 0 & Y.3.1 & التعدديه في البيئه & \multirow{6}{*}{ البصري } & \\
\hline \multirow[t]{2}{*}{0} & Y.3.2 & الاختلاف في النظام & & \\
\hline & Y.3.3 & ا التاثير الحضاري & & \\
\hline 0 & Y.3.4 & الادراك البيئي & & \\
\hline 0 & Y.3.5 & الاتماط الحسيه & & \\
\hline 4 & 5 & المجموع & & \\
\hline 0 & Y.4.1 & وجود التفاصيل & \multirow[t]{7}{*}{ المتعه البصريه } & \\
\hline 0 & Y.4.2 & انساق المواد والالاوان & & \\
\hline 0 & Y.4.3 & عمر المبنى & & \\
\hline \multirow[t]{2}{*}{0} & Y.4.4 & تقسيم العناصر & & \\
\hline & Y.4.5 & الموازنه بين التعقيد و البساطه & & \\
\hline 0 & Y.4.6 & عدد العناصر & & \\
\hline 0 & Y.4.7 & العاقات بين العناصر & & \\
\hline
\end{tabular}




\begin{tabular}{|c|c|c|c|}
\hline 0 & Y.4.8 & الالالات الموضعيه & \\
\hline & Y.4.9 & الرؤيه الثشوليه & \\
\hline 0 & Y.4.10 & الاستعمال الاكثر للعناصر المتتوعه والمميزه & \\
\hline 0 & Y.4.11 & الارنقاء بالعلاقات الذكيه & \\
\hline 0 & Y.4.12 & العلاقات المميزه المتناسبه مع ســـرعه حركـــه & \\
\hline 10 & 12 & 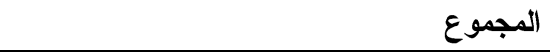 & \\
\hline 0 & Y.5.1 & طبيعه الدور الوظيفي & \multirow{5}{*}{ للعناصر الالايه } \\
\hline & Y.5.2 & التعبيريه الثكليه & \\
\hline 0 & Y.5.3 & الترابط مع عناصر المنظومه الاخرى & \\
\hline 3 & 3 & المجموع - ال الموع & \\
\hline 29 & 40 & المجموع الكلي & \\
\hline
\end{tabular}

جدول رقم (5) يوضح الإطار النظري لمفهوم الذلفيه / (اعداد: الباحثين).

\begin{tabular}{|c|c|c|c|c|}
\hline التحقق & 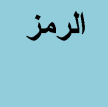 & المؤشرات & الثفرده الثويه & المفرده - الميسيه \\
\hline 0 & Z.1.1 & اعاده استكشاف اهميه المشاهد & \multirow{9}{*}{ اللخاهريه } & \multirow{22}{*}{ الخلقيه } \\
\hline 0 & Z.1.2 & عمليه تنظيم وتصميم المشهر & & \\
\hline & Z.1.3 & تحليل المشهد & & \\
\hline 0 & Z.1.4 & القواعد الموضوعيه لخصائص المشهذ & & \\
\hline 0 & Z.1.5 & البيئه ظاهره فيزيائيه نقيه & & \\
\hline & Z.1.6 & الترابطات الظاهريه & & \\
\hline 0 & Z.1.7 & صوره المدينه الذهنيه & & \\
\hline 0 & Z.1.8 & تدفق المعلومات البصريه & & \\
\hline 6 & 8 & المجموع & & \\
\hline 0 & Z.2.1 & تفسير العناصر المميزه بصريا & \multirow{7}{*}{ الضاله الضمنيه } & \\
\hline & Z.2.2 & الصوره البصريه الفرديه & & \\
\hline & Z.2.3 & الصوره الكليه للمدينه & & \\
\hline 0 & Z.2.4 & تداخل الصور المفرده & & \\
\hline 0 & Z.2.5 & تماسك الابنيه لتحقيق المتعه البصريه & & \\
\hline 0 & Z.2.6 & والجزهام المبنى الواحد في تحقيق شخصيه الكـلـ & & \\
\hline \multirow[t]{2}{*}{4} & 6 & المجموع & & \\
\hline & Z.3.1 & انتاج الرد العاطفي & \multirow{6}{*}{ الطبيعه } & \\
\hline 0 & Z.3.2 & المشهر المتسلسل & & \\
\hline 0 & Z.3.3 & تحليل بنيه مسارات الحركه & & \\
\hline 0 & Z.3.4 & الوحده البصريه وكيفيه الادر (الك & & \\
\hline 0 & Z.3.5 & والاحزاس باوجه بين مدخلات التثكيل وطريقه الادر (ك & & \\
\hline 0 & Z.3.6 & للانتباه و التقرد في المتغير ات الفيزيائيـــه فــي الثــــه & & \\
\hline
\end{tabular}




\begin{tabular}{|c|c|c|c|}
\hline 5 & 6 & المجموع & \multirow{12}{*}{ التصليوريه } \\
\hline 0 & $Z .4 .1$ & قدره التصور & \\
\hline 0 & Z.4.2 & وضوحيه الثكل & \\
\hline \multirow[t]{2}{*}{0} & Z.4.3 & محيط سلوك الفعل الثخصي & \\
\hline & Z.4.4 & الالاله الاجتماعيه & \\
\hline 0 & Z.4.5 & المعنى الثمولي للمدينه & \\
\hline 0 & Z.4.6 & قلره الاجتذاب البصري للمباني الداله & \\
\hline 0 & $Z .4 .7$ & حالده التوازن و الثش مع الموضوعات الداله & \\
\hline 0 & Z.4.8 & تكوين المعنى المكتمل ضمن السياق & \\
\hline 0 & Z.4.9 & النصب و العلاقه مع لوح الخلفيه & \\
\hline 0 & Z.4.10 & الموضوعات القابله للانفصال عن الخلقيه & \\
\hline 9 & 10 & المجموع & \\
\hline 0 & $Z .5 .1$ & 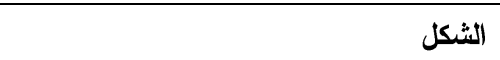 & عوامل \\
\hline 0 & Z.5.2 & خط السماء & ومكونات \\
\hline 0 & Z.5.3 & التناسب & 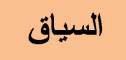 \\
\hline 0 & Z.5.4 & الوحده & \\
\hline 0 & Z.5.5 & التوازن & \\
\hline \multirow[t]{2}{*}{0} & Z.5.6 & المقياس & \\
\hline & Z.5.7 & اللهون & \\
\hline \multirow[t]{3}{*}{0} & Z.5.8 & التفصيل & \\
\hline & Z.5.9 & 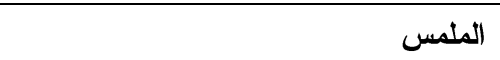 & \\
\hline & Z.5.10 & النموذج & \\
\hline 0 & Z.5.11 & تحديد الموقع المناسب & \\
\hline 0 & Z.5.12 & التكتيل & \\
\hline 0 & Z.5.13 & الايقاع & \\
\hline 0 & Z.5.14 & المو اد & \\
\hline 11 & 14 & المجموع & \\
\hline 34 & 44 & المجموع الكلي & \\
\hline
\end{tabular}

4.3.2. طرح وتحليل ومناقثشه النتائج - (المرحلة الثانية): -

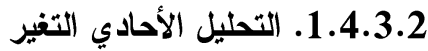

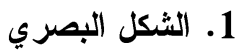

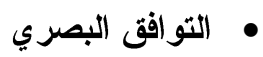

سجلت النتائج تحقـق كـلـ مـن المؤشـرات الاتيـهـ (Y.1.7،Y.1.5 ، Y.1.4،Y.1.3 ، Y.1.2،Y.1.1 ، .Y.1.10) 


$$
\text { • التر ابط والتتابع البصري }
$$

سجلت النتائج تحقـق كــل مـن المؤشــرات الاتيــه (Y.2.8، Y.2.7، Y.2.5، Y.2.4، Y.2.3،Y.2.2

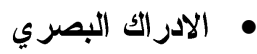

سجلت النتائج تحقق كل من المؤشرات الاتيه (Y.3.5، Y.3.4، Y.3.2،Y.3.1).

• المتعه البصريه

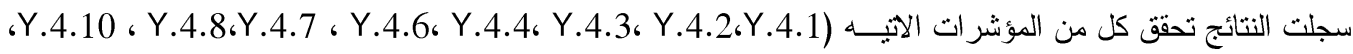

(Y.4.126Y.4.11

• القيمه الالاليه للعناصر

سجلت النتائج تحقق كل من المؤشرات الاتيه (Y.5.36Y.5.1) .

2. الخلفيه

• الحاله الظاهريه للخلفيه

سجت النتائج تحقق كل من المؤشرات الاتيه (Z.1.8، Z.1.7، Z.1.5، Z.1.4، Z.1.2،Z.1.1) .

• الحاله الضمنيه للخلفيه

سجلت النتائج تحقق كل من المؤشرات الاتيه (Z.2.6، Z.2.5، Z.2.4،Z.2.1) .

• الطبيعه الحسبة للخلفيه

سجلت النتائج تحقق كل من المؤشرات الاتيه (Z.3.6، Z.3.5، Z.3.4، Z.3.3،Z.3.2) •

• الطبيعه التصوريه للخلفيه

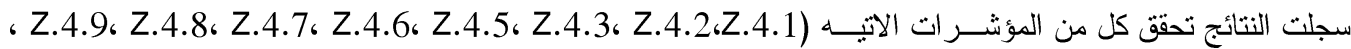

$$
\text { • عوامل ومكونات السياق }
$$

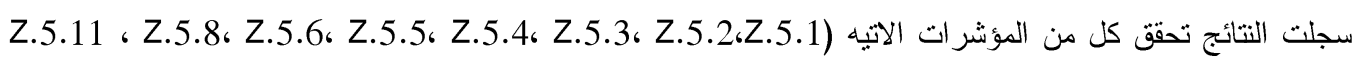

- (Z.5.14، Z.5.1365.12.Z

2.4.3.2 التحليل الثنائي التغير

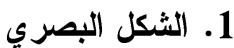

• الثوافق البصري

سجلت النتائج تحقق عدد (7) حالات من مجموع (10) حاله لمتغير التوافق البصري و هذا ما يؤشر الى تحقق قوي كبير . 


\section{• الثر ابط والثتابع البصري}

سجلت النتائج تحقق عدد (7) حالات من مجموع (10) حاله لمتغير التزابط والتتابع البصري وهذا ما يؤشر الى تحقق قوي

سجلت النتائج تحقق عدد (4) حالات من مجموع (5) حاله لمتغير الادر الك البصري وهذا ما يؤشر الى تحقق قوي كبير

سجلت النتائج تحقق عدد (10) حالات من مجموع (12) حاله لمتغير المتعه البصريه وهذا ما يؤشر الى تحقق قوي كبير.

• القيمه الدلاليه للعناصر

سجلت النتائج تحقق عدد (2) حالات من مجموع (3) حاله لمتغير القيمه الدلاليه للعناصر وهذا ما يؤشر الى تحقق قوي كبير ·

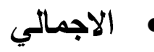

سجلت النتائج تحقق عدد (29) حاله من مجموع (40) حاله لكافة مؤشرات متغيرات مفهوم الثنكل البصري عموما وهذا ما يؤشر الى تحقق قوي كبير ·

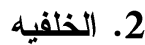

• الحاله الظاهريه للخلفيه

سجلت النتائج تحقق عدد (6) حالات من مجموع (8) حاله لمتغير الحاله الظاهريه للخلفيه وهذا ما يؤشر الى تحقق قوي كبير ·

• - الحاله الضمنيه للخلفيه

سجلت النتائج تحقق عدد (4) حالات من مجموع (6) حاله لمتغير الحاله الضمنيه للخلفيه وهذا ما يؤشر الى تحقق قوي كبير •

\section{• الطبيعه الحسية للخلفيه}

سجلت النتائج تحقق عدد (5) حالات من مجموع (6) حاله لمتغير الطبيعه الحسية للخفيه وهذا ما يؤشر الى تحقق قوي

كبيز جدا.

• الطبيعه التصوريه للخلفيه

سجلت النتائج تحقق عدد (9) حالات من مجموع (10) حاله لمتغير الطبيعه التصوريه للخلفيه وهذا ما يؤشر الى تحقق

قوي كبير جدا.

• عوامل ومكونات السباق

سجلت النتائج تحقق عدد (11) حالات من مجموع (14) حاله لمتغير عوامل ومكونات السياق وهذا ما يؤشر الى تحقق 
سجلت النتائج تحقق عدد (34) حاله من مجموع (44) حاله لكافة مؤشرات متغيرات مفهوم الخلفيه البصريه عموما وهذا ما يؤشر الى تحقق قوي كبير.

3. - 3 - 1استنتاجات

1. الهوية كمفهوم معبر عن خصوصية الثيء وجو هره ووجوده المنفرد يؤشر امتلاك الاصلة كصفة أساسية له تتعكس ربما فـي

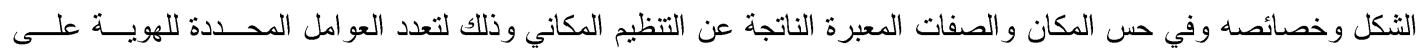

التكوينات الثكلية و الظروف الموقعية و التز ابط المميز لاجز اء المنظومة وفئه الخاصده بها.

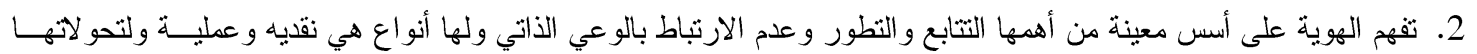

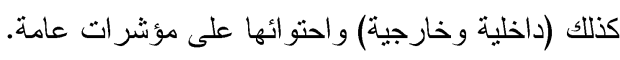

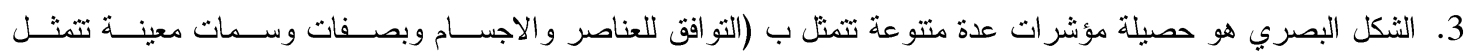

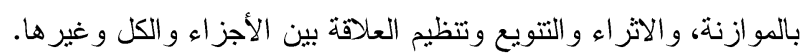

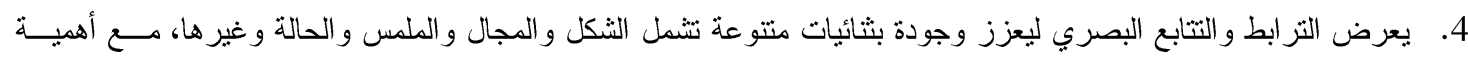

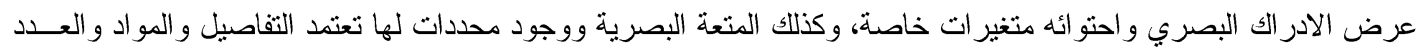

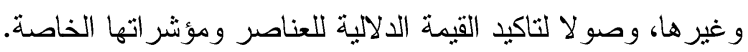

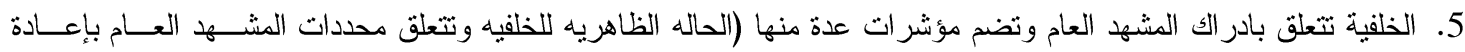

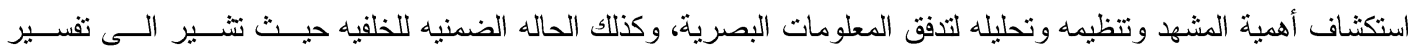

العناصر المميزه بصريا والى طبيعة الصور البصريه الفردية ونظيرتها الكلية للمدينة وتداخلهما.

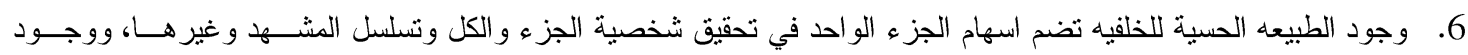

الطبيعه التصوريه للخلفيه لتضم قدرة التصوير وموضو عية للثكل وقدرة الانجذاب البصري للمباني الدالــة، ووجـــود عوامـلـل

ومكونات السياق التي تتعدد وتتتوع بين الثكل وخط السماء و التتاسب و الوحده و غيرها.

7. هناك حاله مثتبه بثكل اولي عن التبادليه بالتزرابط والعلاقه بين مفهوم البحث الاساسي (الهويه) وكل مــن مفهـومي (الثـــكل)

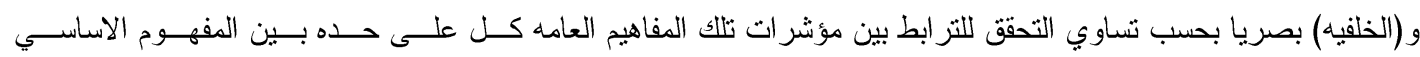
و المفهومين الثانويين.

8. هناك تقارب في طبيعه ومستوى النتائج للمفردتين الخاصه بالمدى المتاح للتغير و التبادليه لمفهوم الهويه وهـــا يــدل علــى ان

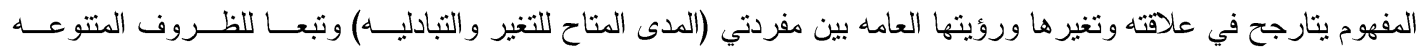

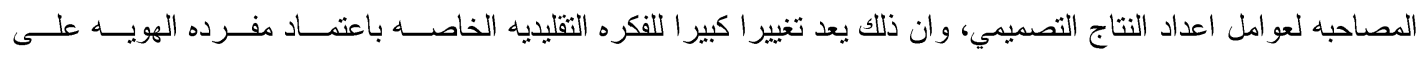

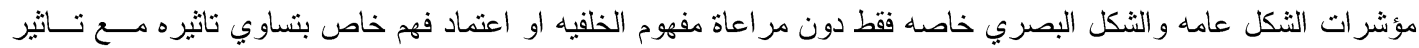
مفهوم الثكل.

4.

1. يوصي البحث بضرورة التوسع في دراسه وتحديد المفردات و المفاهيم العامه الاخرى التي يمكن ان تؤثر بشكل تبادلي وثتـائي في نتكيل اسس الهويه المعماريه العامه.

2. يوصي البحث بضرورة دراسة امكانيه تاثير مفردتي الثكل البصري والخافيه على جو انب اخرى منتوعة يمكن ان تساهم فـي تعريف الاطر المعرفيه العامه في حقل العمارهومنها الجانب الفكري و التصميمي.

\section{CONFLICT OF INTERESTS.}

- There are no conflicts of interest. 
5

الموسو عة الفلسفيتس العربية، بيروت، ص822، 1986.

[2] ر رزوقي، غادة موسى، "فكر الإبداع في العمارة"، رسالة دكتور اه، قسم الهندسة المعمارية، جامعة بغداد، ص27، 1996.

[3] محمد عبد العزيز ربيع "التقافة وأزمة الهوية العربية"، مجلة المنتدى، منتدى الفكر العربي، عمان، الاردن، العدد 179،

[4] Abel, Chris, "Architecture and Identity", towards global eco-culture, Architecture-Press ITD, London, p.145, 1997.

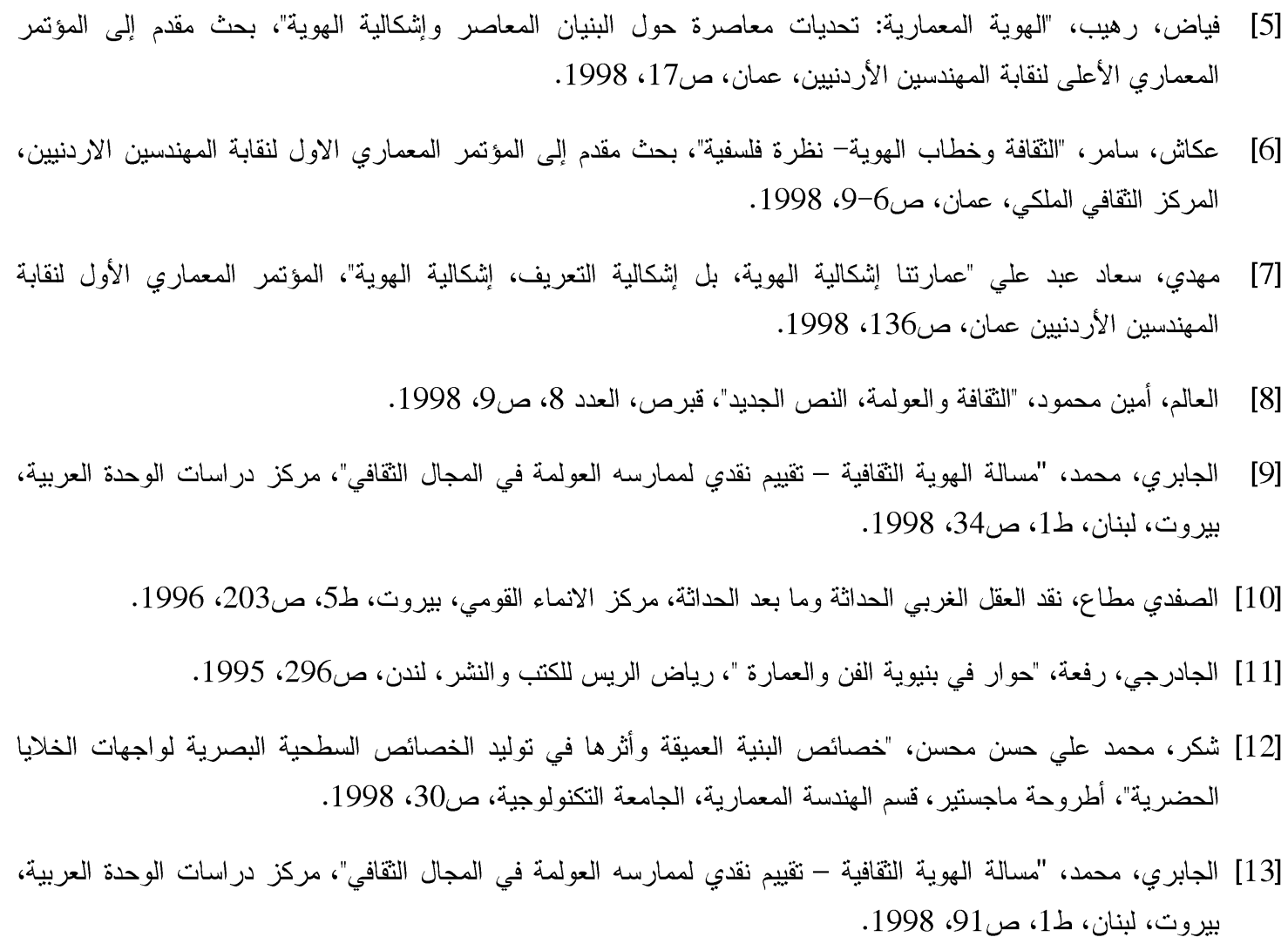

[14] Abel, Chris, "Architecture and Identity", towards global eco-culture, Architecture-Press ITD, London, p.147, 1997.

[15] Schulz Christian, "Genins Ioci-Toward a Phenomenology Architecture", U.S.A Rizzoli international Publishing Inc, p.169-179, 1980.

[16] Correa, C., "Quest for Identity, In Architecture and Identity", Proceedings of the Regional Seminar in the Series Exploring Architecture in Islamic Cultures, Singapore, Concept Media Ltd, p.25, 1983.

[17] Jencks, Charles, "Theories and Manifestos of Contemporary Architecture" Academy Edition, Great Britain, p.150, 1997.

الحيدري، سناء ساطع، "الانتماء المكاني"، أطروحة دكتور اه، قسم الهندسة المعمارية، الجامعة التكنولوجية، ص23، 1996.

[19] Correa, Charles, "Quest for Identity", Cambridge, p.13, 1990.

الحمـــد، نركي"هويـــة بلا هويــة: نحن والعولمــة" ورقــة قدمت الى مؤتمر العولمــة، القاهــرة، أبريل، ص28، 
[21] Abel, Chris, "Architecture and Identity", towards global eco-culture, Architecture-Press ITD, London, p.145, 1997.

[22] Lang, John, "Creating Architectural Theory", New York, Van Nostrand and Reinhold Company, p.196, 1987.

[23] Logie. G., "The Urban Scene", Faber \& Faber Limited, London, p.85, 1971.

[24] Salingaros, Nikos, "Principles of Urban Structure", online book, p.2, 2000.

[25] Malnar J., Vodvarka, F., "Sensory Design", University of Minnesota, U.S.A., p.233, 2004.

[26] Rapaport, Amos, "Human Aspects of Urban Form", the pergamme press, LTD England, p.299, 1977.

[27] Askari A., Dola K., "Influence of Building Façade Visual Elements on Its Historical Image: Case of Kuala Lumpur City, Malaysia”, Journal of Design and Built Environment, Vol.5, p.50-51, 2009.

[28] "Urban Design Handbook", Planning Commission, Parish of East Baton Rouge, City of Baton Rouge, U.S.A., p.5, 2009.

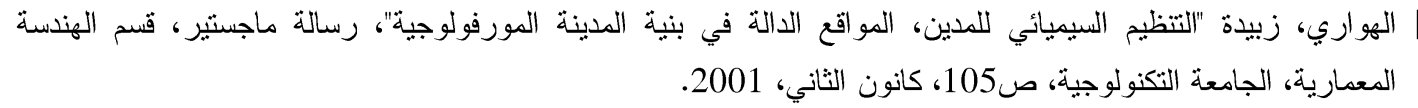

[30] Charlotte M., Annabel B., Robin H., Ben H., and Hamilton B., "Designs for Life: Learning from Best Practice Streetscape Design", UCL Press, London, p.8, 2010.

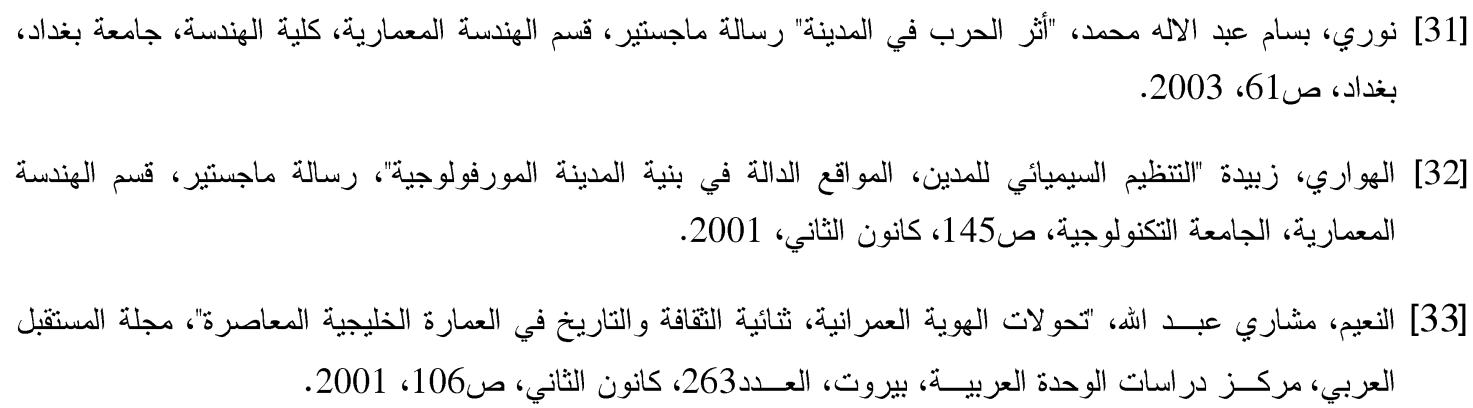

[34] Salingaros, Nikos, "Principles of Urban Structure", online book, p.3, 2000.

[35] Rapaport, Amos, "Human Aspects of Urban Form", the pergamme press, LTD England, p.110, 1977.

[36] Tucker C., "Developing Computational Image Segmentation Techniques for the Analysis of the Visual Properties of Dwelling Facades within a Streetscape", School of Architecture and Built Environment, University of Newcastle, Australia, p.40, 2010.

[37] Cullen, G., "Townscape", Architectural Press, London, pp.11-24, 1961.

[38] Salingaros, Nikos, "Principles of Urban Structure", online book, p.4, 2000.

[39] Lynch, K., "The Image of the City", The MIT Press, p.46, 1960.

[40] McLusky, Jim, "Road Form and Townscape", Architectural Press, London, p.80, 1979.

[41] Broadbent, G., Sgin, "Symbol and Architecture", John Wiley and Sons, New York, p.135, 1980.

$$
\text { [42] نوري، بسام عبد الاله محمد، "أثز الحرب في المدينة" رسالة ماجستير، قسم الهندسة المعمارية، كلية الهندسة، جامعة بغداد، }
$$

[43] Lang, John, "Creating Architectural Theory", New York, Van Nostrand and Reinhold Company, p.94, 1987. 
[44] الهواري، زبيدة "التظظيم السيميائي للمدين، المواقع الدالة في بنية المدينة المورفولوجية"، رسالة ماجستير، قسم الهندسة

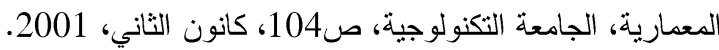

[45] Qian G., "Streetscape and Urban Design", School of Architecture, McGill University, Montreal, Canada, pp. 8-12, 2010.

[46] Tucker C., Ostwald M., "Spatial Configuration within Residential Facades", University of Newcastle, School of Architecture \& Built Environment, Newcastle, Australia, pp.1-2, 2004.

[47] Rezazadeh R., "Perceptual Dimensions of Streetscape in Relation to Preference and Identity: A Case Study in Shiraz-Iran", International Journal of Academic Research, Vol.3, No.2, Part III, pp.749757, 2011.

[48] Cullen, Gorden, "The Concise Town Scape", The Architectural, Press, London, p44, 1973.

[49] البلوري، ابتهاج، "العمارة السياقية"، رسالة ماجستير، جامعة بغداد، كلية الهندسة، قسم الهندسة المعمارية، بغداد، العراق،

[50] Mies, Piers,"Elements of Architecture", E\&FN SPON, London, p.50, 1996.

$$
\begin{aligned}
& \text { [51] معين، ندى، "تبادلية العلاقة للشكل الحضري و المعماري"، رسالة ماجستير، الجامعة التكنولوجية، قسم الهندسة المعمارية، بغداد، }
\end{aligned}
$$

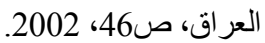

$$
\begin{aligned}
& \text { [52] الماجدي، باسم حسن هاشم، "ثنائية النظرية والتقاليد في العمارة المعاصرة"، أطروحة دكتور اه، قسم الهندسة المعمارية، الجامعة } \\
& \text { التكنلوجية، بغداد، ص202، بالئ } 2009 .
\end{aligned}
$$

[53] https://www.diplomatie .gouv.fr

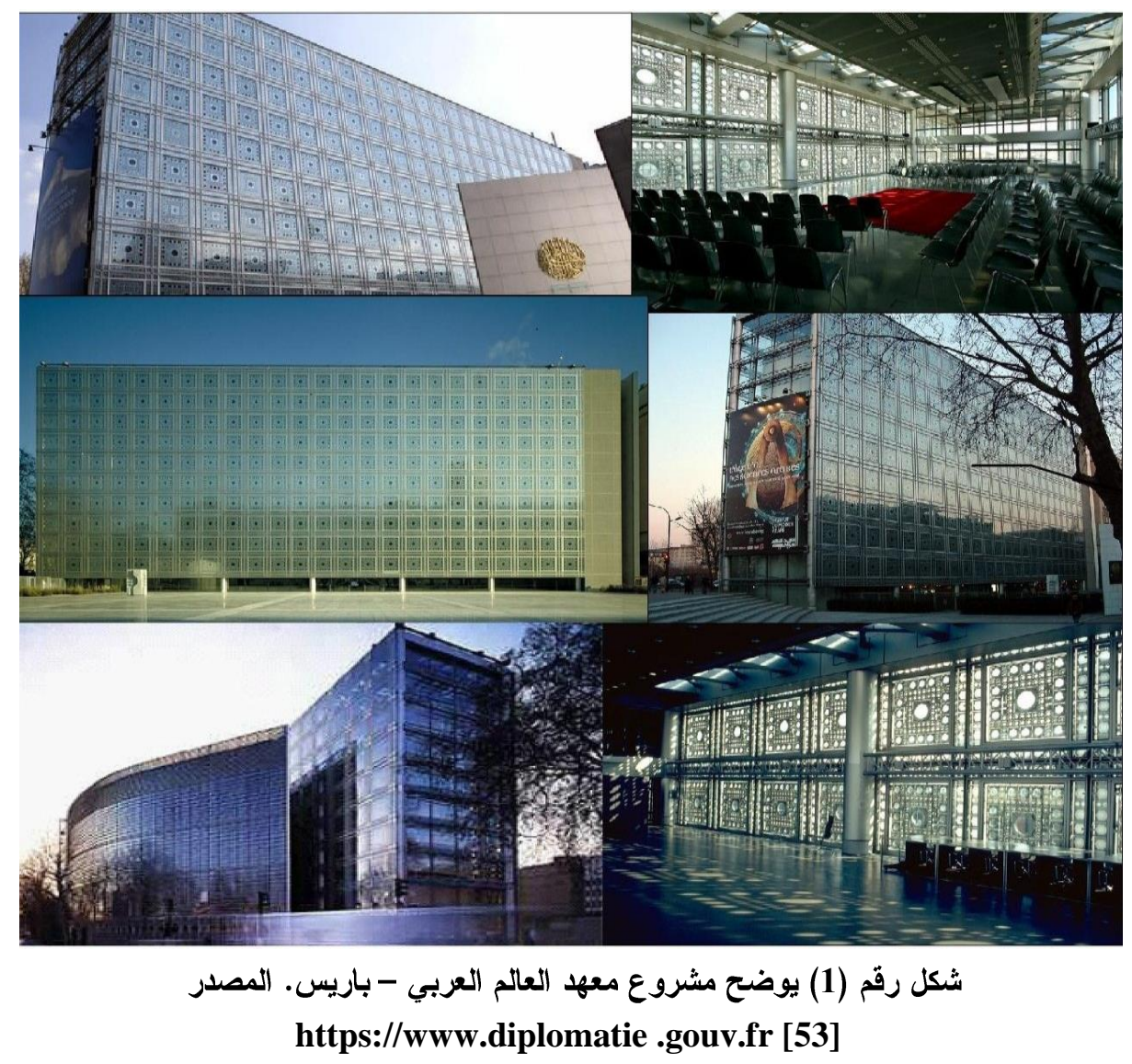

